\title{
La II República en Andalucía (1931-1936) (Reflexiones, sugerencias y fuentes para el estudio de los procesos electorales)
}

\author{
MARIO NICOLAS LOPEZ MARTINEZ \\ LEANDRO ALVAREZ REY
}

\section{ALGUNAS MATIZACIONES A LA SOCIOLOGIA ELECTORAL SOBRE EL QUINQUENIO REPUBLICANO: „CAMPESINOS SI, CIUDADANOS NO*}

Muy recientemente, Aurora GARRIDO MARTIN, en un encuentro auspiciado por la Universidad de Cantabria realizó un balance sobre la $L a$ sociología electoral de la Restauración ${ }^{2}$. En él, entre otras cuestiones, aborda cómo se produjo el nacimiento de la sociología electoral en'España a partir de la entrada en los años sesenta de bibliografía francesa y anglosajona, así como la aparición en 1969 del libro de Miguel MARTINEZ CUADRADO sobre "Elecciones y partidos en España, 1868-1931", que suponía el inicio de los métodos de la sociología electoral europea dentro de la historiografía nacional ${ }^{2}$. Siendo, desde entonces hasta nuestros días, los estudios sobre elecciones uno de los campos preferentes de trabajo de los investiga dores de nuestra historia contemporánea. Siguiendo a esta misma autora, una de las causas profundas de esta preocupación historiográfica

(1) Aurora GARRIDO' MARTIN: -La sociología electoral de la Restauración: los estudios sobre el caciquismo., en Germán RUEDA (editor): Doce estudios de historiografía contemporánea, Madrid, Universidad de Cantabria-Asamblea Regional de Cantabria, 1991, pp. 169-182.

(2) Para más detalles sobre las aportaciones, los inicios y recorridos historiográficos en materia socio-electoral se pueden consultar en Alicia YANINI: -La Restauración monárquica y el caciquismo (revisión bibliográfica), en Estudis d'História Contemporánea del País Valenciá n $n^{2}$, Valencia (1979), Pp. 293-312. De la misma autora y más recientemente: -La manipulación electoral en España: sufragio universal y participación ciudadana (1891-1923), en J. TUSELL (ed.): El sufragio universal, en $A y e r, \mathrm{n}^{2} 3$, Madrid (1991), pp. 99-114. Y, del mismo Javier TUSELL, en esa misma revista su artículo: "El sufragio universal en España (1891-1936): un balance historiográfico•, pp. 13-62. 
estuvo marcada y, cito textualmente: "en un intento de indagar en nuestro pasado mâs reciente las causas de la debilidad, el fracaso y el atraso de la democracia en España en el marco de una Europa Occidental mayoritariamente democrática tras la Segunda Guerra Mundial. Así, continúa la cita- no resulta extraño que sean las elecciones celebradas durante la II República las que inicialmente se constituyan en objeto de estudio prioritario, para que a partir de aquí se intente reconstruir todo un pasado político.3. Lo que implicaba, a nuestro modo de ver y, tras la larga noche franquista, una reconstrucción histórica -en muchas ocasiones- poco real, por cuanto la lectura "modernizadora» de la República en contraste con etapas anteriores sin dejar de ser real es bastante matizable 4 .

Este mismo trabajo al que venimos haciendo referencia trata, más adelante, de las aportaciones sobre caciquismo electoral en el período de la Restauración. Como no podría ser de otra manera reconstruye los condicionamientos reales de sistema político y de la expresión electoral de cuerpo social a través de la crítica realizada al caciquismo por los pioneros trabajos de tres investigadores ya consagrados: J. TUSELL, J. VARELA ORTEGA y J. ROMERO MAURA. Sin querer pecar de simplista, dichas investigaciones hicieron hincapié sobre la imposición relativamente pacífica de la voluntad de un minoría oligárquica sobre el cuerpo electoral de la nación; sobre el escaso papel desempeñado en consecuencia por la violencia, la coacción económica o de cualquier otro signo y la corrupción electoral "expresas" tendentes a anular, a atropellar una supuesta opinión política del país. A su vez, dichos trabajos incorporaron al utillaje de la investigación sobre este tema importantes fuentes, muchas de ellas inéditas, de origen oficial y privado.

VARELA ORTEGA concibe el caciquismo como un fenómeno de "patronazgo", esto es, de intercambio de bienes y servicios entre el cacique y sus seguidores o simplemente los electores. Una relación que se asentaría, entre otras cosas, en el efavor. derivado del control de la maquinaria administrativa que sería el factor esencial en la creación y mantenimiento de las clientelas políticas. Asimismo, el fraude electoral ocupa un lugar destacado en su análisis, matizando no obstante que se trataba de un falseamiento de las elecciones más que de la opinión. En conclusión, los componentes esenciales del sistema político de la Restauración serían, para este autor: el pacto electoral, la desmovilización polí-

(3) A. GARRIDO MARTIN: op. cit p. 171.

(4) A demostrar esto hemos dedicado un buen número de páginas en Mario LOPEZ MARTINEZ: Elecciones, caciques y campesinos en Granada durante la II República (1931-1936). Orden püblico y control social en las comunidades rurales. Granada, Tesis Doctoral Microfichada, 1992. 
tica, el caciquismo como un fenómeno de patronazgo y la represión como una excepcións.

ROMERO MAURA, descarta también como una explicación general del caciquismo la coacción en sus múltiples manifestaciones y el fraude con la intencionalidad de adulterar la voluntad expresada por los electores, la deferencia patriarcal o la explicación psicologista basada en la falta de voluntad de los españoles. Coincide, pues, con VARELA en considerar esencialmente al caciquismo como un fenómeno de clientelismo político basado en el control ejercido por los caciques sobre las decisiones de la Administración. Según R. MAURA eran :muchos* y *de todas las clases sociales* lo que se beneficiaban personalmente y a título individual del control que el cacique tenía sobre los aparatos administrativos ${ }^{6}$.

TUSELL elabora un completo análisis sobre la práctica del *encasillado", como resultado del pacto entre la élite política nacional y las oligarquías de los dos partidos del turnismo establecidas en las diversas provincias: Asimismo, resaltó la dicotomía existente entre el comportamiento político "urbano* y el rural en la Andalucía del primer tercio del actual siglo, señalando la docilidad de las zonas rurales a la práctica del encasillado oficial. En las capitales de provincia, la práctica electoral presentaba según sus trabajos- una mayor semejanza con la propia de una sociedad democrática y los resultados electorales, en consecuencia, expresaban también en mayor medida la voluntad política del cuerpo electoral que los registrados en los distritos rurales, donde las elecciones con apariencia de normalidad democrática eran excepcionales. Este mismo autor destaca el importante papel jugado de cara a la estabilidad del sistema por la división electoral en unas circunscripciones urbanas que junto a las capitales de provincia incorpo: an una serie de pueblos con el fin de asfixiar el voto urbano ${ }^{7}$. En cuanto a las zonas rurales, la pasividad absoluta del electorado

(5) Posiciones defendidas en Los amigos políticas. Partidos, eleccínes y caciquismo en la Restauración (1875-1900) Madrid, A 'ianza Universidad, 1977 y $\cdot$ Los amigos políticos: funcionamiento del sistema caciquista., en Revista de Occidente $\mathrm{n}^{\circ} 127$, Madrid (1973), pp. 45-7.4.

(6) La selección de trabajos donde ha desarrollado tales ideas sè pueden ver en: El caciquismo: tentativa de conceptualización., en Revista de Occidente, $\mathrm{n}^{\circ} 43$, Madrid (1973), pp. 14-44; El caciquismo. en Historia General de España y América. (tomo XVI2), Madrid, Rialp, 1981, pp. 71-88; y, -Patronazgo y poder, en Ernest GELLNER (et. alii.): Patronos y clientes en Las sociedades mediterráneas. Madrid, Ediciones. Júcar, 1985, pp. 79-91.

(7) Efectivamente esta última tesis es buena: la peculiar división de varios distritos por cada provincia manifestaba la hegemonía y la alto representación de la burguesía agraria frente al resto de sus thermanas. (industri l, comercial, etc.) ubicadas en las ciudades.

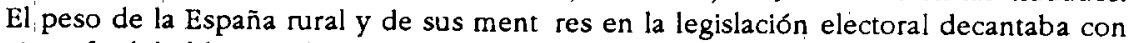
cierta facilidad los resultados en favor ' ' aquélla. Pero, además, los distritos ubicados en las capitales de provincia, donde él d sarrollo de las fuerzas productivas, la diversi- 
daba paso a la generalización en ellas del fraude como explicación de los resultados electorales. TUSELL subraya la falsedad del argumento consistente en equiparar exclusivamente caciquismo a coacción económica y en considerar al latifundio, donde, por otra parte, era típica esa forma de presión, como la estructura socio-económica básica del mismo ${ }^{8}$. Hace igualmente precisiones sobre la gradación o niveles de falseamiento de las elecciones dentro de los distritos rurales, proponiendo al respecto 5 criterios: el sfraude probado", la «docilidad al Gobierno", la "competitividad", la "estabilidad o permanencia. de un determinado candidato y la "vinculación política de los elegidos*. En los dos primeros casos se tratarían de signos de un comportamiento político arcaico, a la vez que los dos últimos lo serían, por contra, de un comportamiento relativamente más moderno. Por último señalaremos que TUSELL establece una estrecha relación entre el grado de modernización del comportamiento electoral y el nivel de desarrollo global, social, económico y cultural, lo que, por extensión le lleva a interpretar el caciquismo como el sistema político acorde con el grado de desarrollo (o subdesarrollo) socioeconómico de la España de la época?.

A partir de estos trabajos pioneros, las investigaciones realizadas hasta el momento, incluidas en cierta medida y con diversas variaciones los referidos a la Segunda República, sólo que en este caso concreto se aplican criterios plenamente modernizadores al comportamiento electoral y, en general, se da como satisfactoriamente probada la muerte del caciquismo por cuanto que éste estaba basado fundamentalmente en la monopolización de los aparatos administrativos del Estado a nivel local, como decimos las investigaciones realizadas presentan unas características bastante similares. La mayoría de ellas incluyen una descripción del marco geográfico y de la estructura socio-económica (demografía, analfabetismo,

dad social y las alternativas de vida y trabajo eran mayores eran rodeados por un buen número de pueblos, no sólo de campiña o de vega (nos referimos, por supuesto, a Andalucía), sino incluso de montaña, esto es, todos aquellos lugares en los que seguían funcionando fuertes dependencias económico-políticas, donde el voto era menos secreto, donde la tierra y su control o monopolización actuaban condicionando la voluntad y el proceso de las luchas. Véase Cuadro I en el Apéndice de este trabajo.

(8) Cfr. J. TUSELL: Oligarquia y caciquismo en Andalucía (1890-1923) Barcelona, Planeta, 1976, p. 265 (señala: -Resulta, por tanto, que el papel del latifundismo en la existencia del caciquismo es mucho menor de lo que, en principio, se podria pensar).

(9) Sobre la producción de J. TUSELL GOMEZ véanse su trabajo citado en la nota anterior y, además la siguiente selección: La crisis del caciquismo andaluz (1923-1931). Madrid, Cupsa, 1977; Sociologia electoral de Madrid, 1903-1931. Madrid, Edicusa, 1969; -La descomposición del sistema caciquil español (1902-1931). en Revista de Occidente, $\mathrm{n}^{2}$ 43, Madrid (1973), pp. 75-93; -El sistema político español en el reinado de Alfonso XIII. en J.A. LACOMBA (et alii): Historia Social de España siglo XX. Madrid, Editorial Guadiana, 1976, pp. 61-82; y, El funcionamiento del sistema caciquil en Andalucía, en Politica y saciedad en la España del siglo XX Madrid, Editorial Akal, 1978, pp. 11-43. 
estructura de la propiedad agraria, etc.) con el fin de delimitar el ecosistema que enmarca al grupo humano cuyo comportamiento político es examinado y establecer las relaciones pertinentes entre los diferentes componentes del mismo y el aspecto concreto a estudiar. De este modo, estos trabajos muestran un mismo esquema temático básico (sería preferible llamarle una metodología común): contexto político nacional o provincial precedente a la convocatoria de las elecciones, la legislación electoral, el proceso de formación de candidaturas, la campaña electoral, los resultados, etc.

Sin duda, este conjunto de obras han aportado y recopilado un gran número de datos que contribuyen a que conozcamos más exactamente la realidad política republicana; sin embargo, como señala Miguel Angel MATEOS RODRIGUEZ ${ }^{10}$ en un recientísimo trabajo que llegó antesdeayer a nuestras y, con el que coincidimos cuando señala, literalmente, que eel modelo de investigación se fijó, con cierto mimetismo, en la escuela francesa dedicada a la sociología electoral, con preferencia por la geografía y la ecología en la línea de ciertos politólogos de nuestro vecino Estado, para continuar considerando que a pesar de que han habido interesantes $y$ destacadas preocupaciones interdisciplinares entre los diversos centros de investigación (Historia, Derecho, Sociología, etc.), •sin embargo, la renovación de los viejos modelos y la superación de manidos esquemas no han tenido igual fortunan.

Ya desde los años setenta se impuso una determinada monografía que comprendía, por lo general, el espacio provincial, coincidente con la circunscripción. Se insistió en los distritos urbanos con descripción de sus secciones y-la correspondiente sociología electoral -propiamente socioprofesional-. Se abandonaron, con alguna excepción, los espacios rurales, pues su estudio resultaba más arduo y laborioso tanto en el hallazgo, cotejo y elaboración de las fuentes como en el modelo metodológico, sin duda más ale,a do de los patrones formulados para las secciones de la ciudad, olvidando en gran medida que la España de los años treinta era un tpaís rural• a pesar de cómo se proclamó la República.

Las páginas que vienen a continuación no tienen, en absoluto, la pretensión de servir de modelo a determinados comportamientos político

(10) .Fuentes y metodología para el estudio electoral de la II República española. en J. TUSELL (ed.): •El sufragio universal., Ayer, n 3, Madrid (1991), pp. 139-16؛, cita posterior en la pág. 140. Tenemos que señalar que, curiosamente y sin haber mantentdo contactos, el trabajo de Miguel Angel MATEOS RODRIGUEZ llega a similares ccnclusiones a las nuestras, singularmente en la búsqueda de nuevas fuentes para el estudio de los procesos electorales y en la importancia de la España rural para comprender los vaivenes electorales de la República o el control de los poderes locales. A estos temas dedicaremos, en gran parte, las próximas páginas desde metodologías y perspectivas algo dispares al trabajo citado. 
electorales de procedencia rural, ni tampoco están elaboradas con fines sustitutivos de los modelos sobre estudios de sociología electoral (¿funcionalista?) ya establecidos. En todo caso, la necesaria renovación metodológica habrá de hacerse como fruto de la discusión y el debate, no ya en este Congreso, sino en sucesivos certámenes que aborden muy distintas líneas de investigación. No obstante, no dejamos, por ello de animar a que se discuta e incluso se polemice sobre las páginas que a continuación exponemos, aún con la certeza que algunas de las posiciones adoptadas podrán resultar atrevidas.

\section{LOS SISTEMAS LOCAIES DE DOMINACION DE CLASE GENERADOS POR EL LATIFUNDISMO}

Debemos, en gran medida, al catedrático de sociología rural Eduardo SEVILLA GUZMAN ${ }^{11}$ (cordobés de adopción) algunas de las reflexiones más profundas y acertadas en torno al concepto sociológico de latifundismo ${ }^{12}:$ por éste entiende una estructura socioeconómica generada por la acción estructurante de la propiedad de la tierra en aquellas "comunidades rurales" en las que se da un predominio de la gran extensión (pudiendo variar este criterio), cuyas fincas forman parte de dicha comunidad creando en la misma un sistema local de dominación de clase ejercido por un grupo de terratenientes que monopolizan los medios de producción agrarios con la fiel asistencia, a través de unas específicas relaciones sociales de dependencian, de unas determinadas

(11) Algunas de sus obras más importantes pueden ser: La evolución del campesinado en España. Elementos para una sociología política del campesinado. Barcelona, Península, 1979; El campesinado: elementos para su reconstrucción teórica en el pensamiento social., en Agricultura y sociedad, $\mathrm{n}^{\mathrm{9}} 27$, Madrid (1983), pp. 33-78; :El campesinado- en Salustiano del CAMPO (ed.): Tratado de sociología Madrid, Taurus, 1988, pp. 366-399 $y$, en colaboración con Howard NEWBY: Introducción a la sociología rural. Madrid, Alianza Universidad, 1983.

(12) Este concepto sociológico se debe también a los estudios y colaboración entre varios sociólogos e historiadores, entre ellos: Manuel PEREZ YRUELA, Manuel GONZALEZ de MOLINA y Karl HEISEL, entre otros. Algunas de las obras que aquí seleccionamos son bastante orientativas: de M. PEREZ YRUELA: -El conflicto en el campesinado- en Agricultura y sociedad, $\mathrm{n}^{\mathrm{2}}$ 10, Madrid (1979), pp. 245-271; -Notas para la construcción de un concepto sociológico de latifundismo., en Revista de Estudios Agro-sociales $\mathrm{n}^{\mathbf{2}}$ 105, Madrid (1979), e YRUELA-SEVILLA: Para una definición sociológica del campesinado., en Agricultura $y$ sociedad $n^{\circ} 1$, Madrid (1976), pp. 15-39. SEVILLA-GONZALEZ-HEISEL: -El latifundismo andaluz en el pesnamiento social agrario de la revolución burguesa al regeneracionismo, en Economia e Sociologia $\mathrm{n}^{2}$ 45-46, Evora (1988), pp. 149-194 y SEVILLA-GONZALEZ: Para una teoría del nacionalismo periférico: el caso andaluz- en Aproximación al andalucismo bistórico. Córdoba, Ediciones de la Posada-Ayuntamiento de Córdoba, 1990. 
"clases de servicio en cuyas manos se encuentran las instituciones económicas, culturales y políticas que, en definitiva, controlan la vida de la comunidad configurando un singular orden social cuya organización económica determina la explotación del campesinado ${ }^{13}$.

Esta larga definición, cargada de sugerentes conceptos socio-históricos, tiene la virtualidad de penetrar en el meollo de muchas de las cuestiones que, en parte, permanecen pendientes de estudio en el amplio campo de la historiografía sobre la Segunda República en Andalucía, no sólo en lo que puede hacer referencia a las diversas manifestaciones de la conflictividad campesina, a sus formas de resistencia 0 adaptación contra la penetración del capitalismo, o a la organización de sus luchas, etc., sino, también, respecto a otros muchos temas relacionados con la configuración de la macrofísica y la microfísica del poder, de las formas de dominación, de las relaciones de dependencia, y, como no, de los diversos comportamientos electorales. Dicho de otro modo y, aunque nos adelantemos al tercer punto de esta ponencia, algunas de las cuestiones que debemos interrogarnos al pensar sobre estas cuestiones (lucha por el poder, conflictividad, clases de servicio, etc.) radican en responder ipor qué sirve el Estado a los intereses de las clases dominantes? y ¿cómo funciona el Estado para expandir y consolidar el sistema capitalista?. Dejémoslo, por un momento, en suspenso y retomemos el anterior parágrafo.

Quizá valga la pena detenerse, muy brevemente, en algunos de estos conceptos anteriormente considerados, especialmente los que se refieren al "sistema local de dominación de clase" y al "orden social latifundista*. Elemento clave del concepto sociológico de latifundismo es el establecimiento de las formas locales de dominación de clase que se representan por medio del poder económico que la propiedad de la tierra otorga a la clase latifundista, esto puede combinarse con el férreo control de los medios de producción, la hegemonía del aparato de Estado a nivel local o la sujeción de las instituciones que permiten el acceso a los medios de vida, lo que configura una clara gradación en el ejercicio de esa dominación. Lógicamente, el grado de apropiación de la tierra actúa como un agente estructurante de la comunidad rural en su conjunto marcando unas ciertas pautas de desigualdad, subordinación y ordenación de la estructura social. En estos formatos de representación de la hegemonía de los grandes propietarios rurales intervienen como

(13) E. SEVILLA-GUZMAN: -Reflexiones teóricas sobre el concepto sociológico de latifundismo, en A agricultura latifundiäria na Peninsula lbérica, Centro de estudios de Economía Agrária, Oeiras, 1980, pp. 29-46. 
piezas claves las :clases locales de servicio ${ }^{14}$, que conservan una determinada ubicación social o institucional pero que, en cualquier caso, garantizan y perpetúan los efectos de la dominación y del orden social estructurante. Aquí no solamente podemos ubicar, socialmente, a los más diversos estratos campesinos en sus diferenciaciones internas (jornaleros, yunteros, aparceros, arrendatarios, pequeños propietarios) que pueden establecer "redes de dependencia" y unas determinadas estructuras de poder a través de la "segmentación vertical, frente a la horizontal, segmentación marcada entre otras razones por las formas de explotación de la tierra o por otras circunstanciasis; sino que, además, entre las

(14) El término clases de servicion fue acuñado por Karl RENNER (Cf. Anthony GIDDENS: La estructura de clases en las sociedades avanzadas. Madrid, Alianza editorial, 1989) y profusamente utilizado por Raif DAHRENDORF (Las clases sociales y su conflicto en la sociedad industrial. Madrid, Rialp, 1970) en su teoría sociológica sobre el conflicto social y la coacción, según la cual: toda sociedad está constantemente sometida a procesos de cambio, marcados por los conflictos y las disensiones, en los cuales ciertos elementos de esa sociedad contribuyen al éxito de la coerción. Por tanto, la estructura de las relaciones sociales son producto de relaciones de fuerza, de sumisión y de sujección y, por consiguiente, relaciones conflictivas, de tal manera que el orden social reposa sobre la coerción ante que sobre la colaboración, sin negar rotundamente que ésta pueda exitir.

Sin asumir globalmente la teoría de DAHRENDORF, sí que nos interesa apuntar su noción de clases de servicio, como un cuerpo o una serie de elementos humanos responsables y altamente recompensados, cuya lealtad, aptitudes y, en ocasiones, participación en el poder, sin olvidar su necesario revestimiento de autoridad y legitimidad, garantizaban la posición de las clases dominantes y perpetuaban sus niveles de existencia y properidad.

Pues bien, cualquier clasificación externa que realicemos sobre las clases de servicio se han de hacer teniendo presente que las posiciones de clase de sus miembros no vienen determinadas, directamente, por el lugar que ocupan en las relaciones de producción, sino por su relación con los intereses fundamentales. (E.O. WRIGHT: Clase, crisis $y$ Estada Madrid, S. XXI editores, 1983, p. 85) de las clases definidas dentro de esas mismas relaciones sociales de producción; esto nos permite comprender por qué determinados grupos institucionales (ejército, policía, burocracia, iglesia, etc.) son una fracción del bloque formado por las clases dominantes, al margen de que sus componentes sean de extracción social no burguesa, aunque no detenten la propiedad de los medios de producción, son necesarios para el mantenimiento de la hegemonía haciendo funcionar los aparatos de Estado, ejerciendo un control ideológico sobre las masas o, simplemente, reprimiendo cualquier amenaza al orden social hegemónico.

Por tanto, el Estado capitalista se siente protegido por una serie de estructuras y órganos burocráticos que, muy bien podrían denominarse sservidores del Estado (Ralf MLLIBAND: El Estado en la sociedad capitalista México, S.XXI editores, 1985, 132 ed., pp. 323-24 y 436-39) que aseguran determinados niveles de legitimación del orden social existente, del grado de represión y consenso en la sociedad civil, de los procesos de socialización, de control social, etc. En consecuencia, una importante gama de componentes imprescindibles para asegurar el mantenimiento de la hegemonía de las clases dominantes.

(15) Hamza ALAVI es bastante claro cuando señala que dlas divisiones políticas de las sociedades campesinas suelen ser divisiones verticales, que atraviesan las fronteras de las clases, más bien que divisiones horizontales propias del conflicto de clases. Los 
"clases de servicio. se ubican no sólo la burocracia estatal administrativa y represiva (secretarios de ayuntamiento, jueces municipales, guardia civil, etc.), sino también, aquellos otros elementos pertenecientes a las Casas Grandes y Cortijos latifundiarios, nos referimos a determinados administradores, encargados, manijeros, cortijeros, personal fijo, guardas jurados, etc., que trabajan para el terrateniente, el cual mantiene este tipo de redes o formaciones verticales con un carácter más o menos estable y fijo, carácter que como contrapartida se refleja no sólo en comportamientos laborales determinados (insolidaridad de clase con el resto del campesinado), sino en actitudes políticas y electorales (escopeteros, pistoleros, etc.) tanto de las "clases domésticas", como de las "clases de servicio".

Es, en definitiva, el nivel de apropiación de la tierra ${ }^{16}$, así como la complejidad con que éste se manifieste, el que puede marcar la mayor o menor penetración del sistema de dominación local de clase y, como expresión del mismo, la configuración de las relaciones sociales entre los distintos grupos. Relaciones que se explicitarán tanto en los intereses antagónicos de esas fracciones, como en definitiva en su capacidad de tornarse en "manifiesta", en "externa", la conflictividad que denominamos socialmente slatente.

Por tanto, el orden social latifundista tiene una incuestionable dimensión política, resultado de las complejas articulaciones entre las instituciones político-administrativas locales que pertenecen al Estado-nación (Gobernadores civiles, Guardia civil, Jueces municipales, etc.) y, otras formas no estatales que encauzan relaciones sociales de dependencia igualmente complejas. Ambas esferas, en muchas ocasiones difícilmente diferenciables, se encuentran bajo la poderosa influencia de las clases dominantes locales o provinciales.

Este análisis está adecuado -se nos puede achacar- a aquellas comunidades con estructuras agrarias latifundiarias, pero isirven estas mismas aseveraciones para aquellos espacios socioecológicos con predominio de

líderes de las facciones se conciben como detentadores locales de poder o bien como emprendedores políticos manipuladores, que organizan grupos políticos con sus séquitos de jornaleros, aparceros y otros dependientes económicos -si los tienen-, y alianzas con otros grupos o individuos influyentes. en Las clases campesinas y las lealtcides primordiales. Barcelona, Anagrama, 1976, pp. 89-90.

(16) La obra de Pascual CARRION (Los latifundios en España Barcelona, Ariel, 1975), tantas veces citada, sigue siendo la referencia física más importante para conocer ese grado de apropiación de la tierra en el Sur peninsular, sin embargo, no nos of rece todas las claves de ese proceso, vale la pena citar en este sentido los dos aclaratorios estudios de Antonio Miguel BERNAL, La propiedad de la tierra y las luchas agrarias andaluzas Barcelona, Ariel, 1974 y Economía e bistoria de los latifundios. Madrid, Espasa Calpe, 1988. No hacemos mención de ninguno de los estudios sobre los procesos de desvinculación, desamortización y apropiación de la tierra, así como la conflictividad que todo ello generó por razones de espacio. 
la explotación campesina y de la pequeña propiedad?. Parece claro que en estas comunidades determinadas relaciones políticas y sociales serían más estrechas entre los miembros de la comunidad, ¿aparecen, una vez más, visibles las relaciones verticales? ¿el patronazgo, el clientelismo, las relaciones familiares-sanguíneas, la diferenciación interna es menor? Parece que sí, en este terreno la antropología social nos puede decir mucho; sin embargo, la aldea campesina, la ansiada y deseada mir. (comuna campesina) en el inconsciente colectivo campesino no estaba ajena al resto del mundo, del desarrollo del mercado, del mercado como sistema, del resto de las realidades provinciales, regionales, nacionales, etc. No obstante, concretemos más, parece incuestionable que las relaciones entre la gran propiedad y las formas de producción campesinas en el sur peninsular han sido muy estrechas a lo largo del desigual desarrollo y penetración del capitalismo en la Baja y Alta Andalucía, tan sólo algunas apreciaciones: las formas de explotación de la tierra, los modelos de contratación de la mano de obra jornalero-campesina, las diversas estructuras ecológicas y económicas han estado, por muy diversos motivos, complementadas $^{17}$. En definitiva, la pequeña propiedad campesina a pervivido al modo de producción capitalista gracias, no sólo, a su complementariedad con el latifundismo, sino fundamentalmente a su subordinación a éste ${ }^{18}$. Tan sólo la consideración de este hecho, sin entrar en otras muchas cuestiones, debió tener tantas repercusiones políticas y sociales, durante la República, que merecerían la atención y el estudio a la hora de abordarse cualquier trabajo de sociología electoral que incluyera dentro de su esfera una comunidad rural.

\section{LA REPUBLICA: UN "ESTADO LIBERALMENTE REPRESIVO ${ }^{19}$}

Existe, todavía entre muchos de los estudiosos de los procesos electorales durante la Segunda República, la idea de que el 14 de Abril

(17) Véanse los dos artículos de M. GONZALEZ DE MOLINA y de E. SEVILLA GUZMAN: -Para una teoría del nacionalismo periférico, en E. SEVILLA GUZMAN (ed.): Aproximación sociológica al andalucismo histórico. Córdoba, Ayuntamiento de Córdoba, 1990, pp.37-97 y :Movimiento jornalero y andalucismo histórico, en Justo G. BERAMENDI y Ramón MAIZ (comps.): Los nacionalismos en la España de la II Repüblica. Madrid, S. XXI editores, 1991, pp. 305-331.

(18) Cf. M. GONZALEZ DE MOLINA y E. SEVLLLA GUZMAN: •Minifundio y gran propiedad agraria: estabilidad y cambio en la Alta Andalucía, 1758-1930., en Pegerto SAAVEDRA y Ramón VILLARES (eds.): Señores y campesinos en la Península Ibérica, siglos XVIII-XX. Campesinado y pequeña explotación Barcelona, Crítica, 1992, pp. 88-138.

(19) Una versión extensa de algunos de los argumentos que aquí se van a utilizar se pueden hallar en Mario LOPEZ MARTINEZ: Elecciones, caciques y campesinos en Granada durante la II Repüblica, 1931-1936. Orden público y control social en las comunidades nurales. Granada, Tesis doctoral microfilmada, 1992, pp. 67-128. 
abrió una etapa radicalmente nueva en los comportamientos políticos y en las decisiones que se tomaban desde los "centros operativos" del poder. Sin dejar de ser esto parcialmente cierto, conviene hacer a estas afirmaciones un buen número de matizaciones, después de las cuales la idea sobre el Estado republicano-democrático nos acercará a su verdadera dimensión represiva. En ese sentido el Estado republicano fue un fiel heredero del Estado monárquico oligárquico-militar dotándose de los instrumentos legales que dejaron muy pocos resquicios no sólo a las amenazas de rebelión o insurrección social, sino al pleno desarrollo de las libertades democráticas conquistadas, confirmándose de hecho la continuación de una cierta "represión latenter a la cual, las clases sociales dirigentes, por no entrar en demasiadas especificidades, tenían acostumbrados a sus gobernados ${ }^{20}$.

(20) En realidad esta defensa del Estado por parte de algunos regímenes que inauguraban una nueva etapa tras la' Primer Guerra Mundial optaron, claramente, por una defensa armada del orden social burgués. En este sentido los instrumentos de esa defensa variaron, pero el fin perseguido fue el mismo. Aunque en esa variedad se marcaba la pauta del grado de integración y cohesión social de la sociedad civil, es decir, del grado, naturaleza y carácter en las que se desarrollaron las luchas de clases en cada uno de los países de Europa.

La denominada como Unión Sagrada en Francia (nacionalización del movimiento obrero-sindical, destrucción de la II Internacional, acuerdos político-sociales entre burguesías nacionales y sindicalismo nacional-reformistas, etc.) y extendida a otros países europeos beligerantes alteraron -de forma desigual- las relaciones sobre las que se configuraban las luchas sociales. La .Unión Sagrada. llevaba aparejada toda una serie de medidas de guerra: economía de guerra, participación socialista en las tareas de gobierno, nacionalizaciones, etc. Metas que querían hacer pervivir los obreros tras la Gran Guerra y disposiciones que pretendían abolir los grandes burgueses capitalistas. Al paisaje desolado por la Gran Guerra se añadió la difícil reconstrucción: un espíritu revanchista en Versalles, una crisis estructural de las industrias de base, un fuerte desempleo igualmente estructural, las fuertes deudas contraídas por los países beligerantes, la destrucción del sistema económico internacional basado en el patrón-oro, etc. Los meses siguientes al armisticio fueron tiempos de fuerte agitación social, en países como Francia y Gran Bretaña el sistema de cobertura social amortiguó la situación, en otros más castigados (Alemania, Italia, etc.) por los pagos de reparaciones de guérra la protesta obrera se convirtió en revolución fuertemente reprimida (por ejemplo el espartaquismo).

Mientras los sindicatos solicitaban a los gobiernos nacionalizaciones y estatalizaciones, el mundo empresarial lo interpretaba como el primer paso para experimentar la crevolución roja de Rusia. Las huelgas del ferrocarril (Francia), del carbón (Gran Bretaña), revolucionaria-consejista (Alemania) y general-consejista (Italia) terminaron por adoptar nuevas estrategias de defensa burguesa. Como hongos proliferaron las Unions Civiques, las milicias de voluntarios, los grupos de ex-combatientes, los fasci di combattimento, etc. $y$, en definitiva la promulgación de legislaciones especiales de protección del Estado, traducidas literalmente como medidas de seguridad contra las propiedades e intereses de empresarios y grandes capitalistas. Las huelgas generales, la paralización de los servicios esenciales de un país (energía eléctrica, alimentación, transportes, correos, prensa, etc.) eran considerados como subversivos y. atentatorios contra el orden social existente. Esta legislación especial, trajo consigo tribunales especiales -de ejecución 
Algunas monografías como la de Manuel BALLBÉ sobre el importante papel del Orden Público y la destacada intervención del Ejército en el mismo en la España constitucional ${ }^{21}$ han abierto cauces profundos para

rápida de los procesos- y la adopción de códigos castrenses -mucho más duros y severos en sus penas-. Aquí, igualmente, la gradación de estas medidas estuvo marcada por el grado de integración y vertebración de las clases sociales en esos Estados. En Gran Bretaña se adoptó la Ley Especial de Poderes de Apremio en la que sin negar el derecho a la huelga garantizaba los servicios mínimos, en Fracia la Ley de Seguridad permitió la huelga con restricciones mayores y, en países como Alemania, España o Italia funcionaron duras legislaciones sobre Orden püblico y terrorismo.

Asimismo, cuando esta legislación especial, como tal instrumento represor, no sirvió convincente y convenientemente a los intereses que defendía se optaron por nuevas fórmulas: ¿eran los Estados conscientemente débiles ante el empuje obrero? ¿era la dictadura civil o militar el mejor instrumento para contener la avalancha obrera? Una mirada a los años 20 ó 30 y a países como Alemania, Italia, España, Austria, Portugal, Rumanía, Yugoslavia, etc., etc., parece contestar sobredamente.

En cualquier caso la idea última que queremos exponer en esta larga nota a pie de página es que, al igual que ocurrió en la España oligárquico-militar y en la España republicana, todos los Estados europeos adoptaron medidas especiales para subordinar, por la fuerza, a la mano de obra industrial y campesina. En gran medida, las reformas y esperanzas suscitadas por la Segunda República no hicieron ver con la suficiente prontitud -tal y como ocurrió en 1919 en la República de Weimar-el carácter represivo de un régimen republicano-democrático capitalista. La Guerra civil, el franquismo y la falta de una democracia parlamentaria generaron, quizá, una falsa memoria histórica de esta dimensión de la República.

Cfr. para buena parte de los argumentos expuestos algunas referencias obligadas. Sobre Europa puede verse a Charles S. MAIER: La refundación de la Europa burguesa. Estabilización en Francia, Alemania e Italia en la década posterior a la I Guerra Mundial Madrid, Ministerio de Trabajo y Seguridad Social, 1988; Thomas VOLKMANN-SCHLUCK: -La evolución del proceso alemán en el siglo XX. en Cuadernos de Polútica Criminal $\mathrm{n}^{2}$ 9, Madrid (1979), pp. 75-84; Sh. BEN AMI: -Las dictaduras de los años veinte. en M. CABRERA, S. JULIA y P. MARTIN ACEÑA (comp.): Europa en crisis, 1919-1939 Madrid, Editorial Pablo Iglesias, 1991, pp. 47-64; Juan J. LINZ: La quiebra de las democracias. Madrid, Alianza editorial, 1987. Y, sobre España (igualmente otra selección): Julio AROSTEGUI: -Conflicto social e ideologías de la violencia, 1917-1936•, en J.L. GARCIA DELGADO (comp.): España, 1898-1936. Estructuras y cambia Madrid, Universidad Complutense, 1984, pp. 309-343; Albert BALCELLS: .Violencia y terrorismo en la lucha de clases en Barcelona de 1913 a 1923. en Estudios de Historia social, n 42-43, Madrid (1987), pp. 37-79; Eduardo GONZALEZ CALLEJA: -La defensa armada del -orden social. durante la Dictadura de Primo de Rivera (1923-1930), en J.L. GARCIA DELGADO (ed.): España entre dos siglos (1875-1931). Continuidad y cambio. Madrid, S. XXI editores, 1991, pp. 61-108 y Fernando del REY REGUILLO: Propietarios y patronos. La política de las organizaciones económicas en la España de la Restauración (1914-1923). Madrid, Ministerio de Trabajo y Seguridad Social, 1992.

(21) Manuel BALLBÉ: Orden püblico y militarismo en la España constitucional (1812-1983) Madrid, Alianza Universidad, 1983. Aunque, si bien es el trabajo más específico, no es el único sobre este tema, de igual calidad son las obras que a continuación se mencionan: Diego LOPEZ GARRIDO, El aparato policial en España. Historia, sociología e ideología. Barcelona, Ariel, 1987; Carlos SECO SERRANO, Militarismo y civilismo en la España contemporänea. Madrid, Instituto de Estudios Económicos, 1984 y Michael ALPERT, La reforma militar de Azaña (1931-1933). Madrid, Siglo XXI, 1982. 
que sucesivos estudios, menos generales y más socio-históricos, se interesen por esta realidad estructurante. No descubrimos nada nuevo si señalamos que durante la República se siguieron produciendo deportaciones, confinamientos y detenciones arbitrarias ${ }^{22}$. Así como demasiadas intervenciones de las autoridades militares en cuestiones de Orden público. Se podrá argumentar que, especialmente durante el Primer Bienio, se avanzó a pasos agigantados en materias como la desmilitarización de la sociedad civil (abolición de la Ley de Jurisdicciones), la adopción de nuevos cuerpos policiales menos represivos (Fuerzas de Asalto) o el expreso reconocimiento de ciertas libertades y derechos civiles (Constitución de 1931). Sin dejar de ser cierto, sin embargo, la consulta de determinados archivos como el "Histórico Nacional. (Gobernación Serie A) nos tienen demasiado acostumbrados a desagradables sorpresas y, no digamos lo propio del archivo del Tribunal Supremo y el gran número de suplicatorios de guarda para encausar, a sus señorías diputados, por los más diversos motivos (artículos de prensa, declaraciones antigubernamentales, llamadas a la sedición, etc.).

Por si no bastara la extensa legislación existente sobre orden público, el régimen republicano-democrático se dotó de los pertinentes instrumentos represivos: La "Ley de Defensa de la República" (octubre 1931) fue, evidentemente, un arma de doble filo, con ella se permitió en nombre de la seguridad del Estado continuar con la inveterada política, del régimen precisamente derrumbado, de clausurar sedes sociales, suspender reuniones políticas, mermar las libertades individuales de expresión, suspender órganos de prensa, realizar incontables detenciones gubernativas, etc. Es decir, preeminencia del Ejecutivo, sobre las decisiones del Parlamento y sobre la defensa y custodia de los derechos civiles. Asimismo, no vale la pena detenerse en detalles sobre el, permítasenos decir, escabroso balance necrológico de los enfrentamientos entre las fuerzas de la seguridad del Estado y manifestantes pertenecientes a las clases trabajadoras: en tan sólo los primeros 20 meses de República las cifras arrojaron un balance desconcertante, más de 200 manifestantes muertos de los que la mitad pertenecían exclusivamente a Andalucía. Si extendiéramos al «Bienio Negro* algunos de sus resultados más luctuosos, tan sólo en algunos meses concretos estas cifras se doblarían e incluso se quir.tuplicarían.

(22) Cfr. J.A. PEREZ MATEOS: Los confinados durante la II Repuiblica. Barcelona, Plaza \& Janés, 1977, pp. 65-91, si bien esta monografía es bastante incompleta y se reduce a tratar la cuestión acogiendo los casos de las -personalidades. Entre otras cosas debe decirse que, por desgracia, el Archivo de la Ley de Defensa de la República se perdió durante la Guerra civil y, por consiguiente, se estravió la pista de los deportados, confinados, etc. sin nombre. 
Con ser esto importante y notorio, no conviene olvidar que durante el primer bienio se promulgó la Ley de Orden Público (julio de 1933) que contemplaba, entre otras cosas, los estados de «prevención", "alarma" y «guerran, así como el estado de previa censura de prensa y limitaciones a los derechos políticos de los ciudadanos. Lo más significativo de esta normativa fueron los efectos que tuvieron en manos de las derechas una vez que éstas controlaron Gobierno y Parlamento, convirtiéndose la aplicación de la citada ley en un instrumento represor. Como sabemos, entre enero de 1934 y abril de 1935 se sucederán -sin solución de continuidadlos estados de prevención, alarma y guerra ${ }^{23}$. A estas medidas fueron aparejadas otras de menor rango, pero no por ello de escaso valor e importancia para el tema que centra nuestras hipótesis de trabajo. En concreto se incrementaron las medidas especiales sobre el orden público para reforzar éste: haciendo responsables directos a los Ayuntamientos de la paz pública en los pueblos, militarizando a los guardias y agentes municipales, prohibiendo todos los actos políticos que pudiesen alterar el orden y coordinando todos los servicios referentes a preservar el orden y la seguridad del Estado. Esta labor de desarticulación de cualquier tipo de protesta social se culminó con la inspección y destitución de las corporaciones municipales en manos de los partidos de las izquierdas, para nombrar Comisiones Gestoras afectas a la coalición agrario-radical-

(23) La evidente extralimitación y abuso de lo que debía ser norma excepcional, convirtió de hecho a la República en una democracia vigilada y extendió los tentáculos del poder por el camino de la represión. Efectivamente, durante casi todo el período de gobierno radical-popular-agrario, los estados de prevención, alarma y guerraw, así como el estado de previa censura de prensa y limitaciones a los derechos políticos jalonaron esa etapa entre enero de 1934 y mayo de 1935. Veamos: el día 3 de diciembre de 1933 se declaró el restado de prevención y el día 9 del mismo mes el restado de alarma con motivo de la intentona insurreccional anarquista en todo el territorio nacional. A partir de entonces, el régimen excepcional durante 1934 quedó como sigue: el 6 de enero fue levantado el estado de alarma, pero se declaró el de prevención. Los Decretos de 2 de febrero y 1 de marzo prorrogaron, sucesivamente, por un mes el mencionado estado. El 7 de marzo se volvió a declarar, otra vez, el estado de alarmaw por un mes, y el 25 del mes siguiente el Gobierno firmó otra prórroga del mismo, que fue levantada el 24 de junio, para entonces ser proclamado el de prevención. Dicho estado fue prorrogado otro mes más el 21 de agosto, y un Decreto de 23 de septiembre volvío a conferir más poderes al Ejecutivo al declarar el estado de alarmaw en todo el territorio estatal. $Y$, por fin, el 6 de octubre, con motivo de la huelga general revolucionaria y la insurrección en Asturias y Cataluña fue declarado el estado de guerra que permaneció vigente hasta finalizar el año, ya que el 6 de diciembre se prorrogó por treinta días la mencionada normativa, volviéndose a prorrogar el 5 de enero de 1935. Durante ese mismo año, el 23 de enero se levantó el estado anterior en algunas provincias (entre ellas Granada), pero se sustituyó por otro de calarma, que el 5 de febrero se volverá a prorrogar por un mes más hasta el 1 de marzo que se cambiará por otro de prevención que permaneció vigente hasta mediados de mayo de 1935. En M. BALLBÉ, op. cit. pp. 364 y $377-78$. 
cedista $^{24}$. Asimismo, especialmente importante, significativa y cargada de contenido político fue la renovación extraordinaria de los Juzgados municipales -adoptada en agosto de 1934-. Con ella se quiso asegurar una parcela más de control sobre el campesinado y, se lograron aumentar muy notablemente-, las posibilidades de represión del mismo, ya que la importancia de los jueces municipales en las comunidades rurales era fundamental. Su papel de mediadores en los juicios de faltas, su arbitraje y conciliación, así como su decantamiento en favor del campesinado o de las clases dominantes locales resultaba decisivo para los intereses de los unios o de los otros. Con los Juzgados renovados de forma extraordinaria y en manos del personal de servicio de los intereses patronales y propietarios locales, habría que traducir esta resolución como una fórmula más de cooptación política y económica del campesinado "sin tierra*.

A todo lo indicado más arriba, cabe añadir otro elemento al que ya hemos hecho referencia: el reforzamiento del orden público en las comunidades rurales. Este se hizo, evidentemente, estrechando los lazos de colaboración entre la institución represiva, por excelencia, del Estado en las comunidades locales (la Guardia civil) y los nuevos órganos administrativos de los municipios (las Comisiones gestoras de centro-derecha).

En cuanto a lo que a la Guardia civil se refiere, aumentaron si cabe sus atribuciones y autonomía de actuación en los pueblos (dependiendo siempre estrechamente del Ministerio de Gobernación). Para ello vol rieron a adoptarse una serie de medidas de orden administrativo y de régimen interior. Ejemplos de ello fueron la autorización de la vigilancia de paisano a los miembros de este Instituto para no ser fácilmente reconocidos; se les encomendó, asimismo, el adiestramiento y mando sobre el cuerpo de guardas jurados y peones camineros y se ordenó la disposición de que los guardias y empleados municipales actuarían como auxiliares del orden público bajo la estricta dirección de la Guardia Civil. Por si esto no fuera poco, podemos aportar un dato más: durante el abienio de derechas" la plantilla de la Guardia civil aumentó un $25 \%$ más, porcentaje muy considerable si tenemos presente que durante la etapa AZAÑA las dimensiones

(24) Cf. lo que ya hemos señalado sobre Sevilla y. Cádiz en Leandro ALVAREZ REY: La derecha en Sevilla durante la II República. Bases sociales, ideología y acción politica (1931-1936) Sevilla, Tesis doctoral inédita, 1990, pp. 651-654 (tomo II). Más detalles sobre estas medidas hemos tenido ocasión de exponerlos en Mario LOPEZ MARTINEZ: -La represión institucional del campesinado durante el .Bienio Negro. Granada 19331936", en II Congreso de Historia de Andaluciá Córdoba, abril (1991), en prensa. Muy recientemente $y$, sobre este tema, utilizando nuestra metodología amablemente aceptada, léase a José M AZPIROZ PASCUAL: Poder politico y conflictividad social en Huesca durante la II República. Huesca, Publicaciones del Ayuntamiento de Huesca, 1993, pp. 199-208. 
de este cuerpo se quedaron estancadas. Medidas, por tanto, que facilitaron la colaboración de otros agentes de la autoridad y de otras instancias que fueron puestas al servicio de este Instituto armado para que se asegurase un férreo control del orden público y la seguridad hasta en lo más recóndito del territorio estatal. En muchos casos la omnipresencia, abuso de poder y de sus competencias como Instituto armado y como autoridades garantes del orden público en los pueblos, en estrecha colaboración y dependencia de mando de sus jefes inmediatos y del Gobierno civil de las provincias, les hicieron crear un estado de violencia institucional muy visible a los ojos de los campesinos más desprotegidos. Un ejemplo bien significativo de ello fue la estrecha dependencia, en la apertura de Casas del Pueblo y Sociedades obreras, de los informes elaborados por la Guardia civil y remitidos a los Gobiernos civiles para levantar la clausura gubernativa de dichos centros. Este ejemplo es tan sólo una muestra de la importancia y el poder conque contó este Instituto, especialmente en el período al que hacemos referencia.

Y, en cuanto a la política de Orden público y social de las Comisiones gestoras, los datos con los que hemos contado, para el primer supuesto, confirman un reforzamiento del aparato represivo de los Ayuntamientos, los contratos de personal subalterno y de policía local durante el "Bienio Negro* fueron más que notables, consecuentemente los gastos en esta materia aumentaron. Por ahora sólo podemos aportar datos para la provincia de Granada, pero sospechamos que en otras provincias andaluzas ocurrió otro tanto igual. Contratación, por tanto, de guardería municipal que subordinada a la Guardia civil reforzaría el papel de ésta y prevalencia de la defensa del orden social rural tradicional frente a la política social-reformista del primer bienio ${ }^{25}$.

En definitiva esta política de orden público, así como la política social, sobre la que no hemos tenido oportunidad de hablar o de definirnos, tuvieron como misión última restituir, en todas sus partes, los sistemas locales de dominación de clase de carácter latifundiario. Consiguieron una vuelta al sautoritarismo rural tradicional. en el que primaron, en los grandes fundios agrarios, la explotación desmedida de la mano de obra jornalera, el control social de la mayor parte del campesinado y la represión institucional. Muestra de ello, como ya hemos venido señalando, fueron las distintas medidas legislativas sobre orden público en las comunidades rurales, el cierre de Casas del Pueblo, la clausura de Sociedades Obreras, etc. Una pequeña ojeada al Archivo del Tribunal Supremo, dentro del recinto de la calle Serrano (en Madrid), permite comprobar la cantidad de suplicatorios solicitados al Congreso de los Diputados

(25) Véase sobre la cuestión del personal el Cuadro II del Apéndice. 
para encausar a algunas de sus señorías pertenecientes a las fuerzas políticas obreras por la firma de determinados artículos en la prensa denunciando irregularidades en las detenciones, o sosteniendo en letra de imprenta la comisión de delitos sobre malos tratos y torturas en las comisarías y cuarteles de las fuerzas de seguridad del Estado, etc.

Por ejemplo, una convocatoria como las elecciones de febrero de 1936, se realizó, en algunas provincias andaluzas, en unas circunstancias que muy poco tenían que ver con unos comicios plenamente libres: centros obreros cerrados, ayuntamientos y juzgados municipales en manos del personal de servicio de las clases dominantes locales, asistencia rigurosa de la Guardia civil y de los delegados gubernativos en los mítines campesinos, vigilancia continua de los principales centros de trabajo, líderes encarcelados o detenidos preventivamente (es curioso que los gobernadores republicanos siguieron utilizando las famosas «quincenas.), en definitiva para no cansar más, unas elecciones con síntomas claros -posteriormente confirma dos en muchas provincias- de manipulación y tergiversación de la voluntad popular expresada en las urnas.

\section{VIOLENCIA ELECTORAL Y FORMAS DE COOPTACION DEL CAMPESINADO}

Lo primero que cabría señalar en este punto es que la cooptación* es una sorma de mediación, tanto en el ejercicio del poder del Estado, como en el control que el bloque social dominante* ejerce, en él y desde él, sobre el resto de la sociedad civil, mediación que permite la :integración " política de componentes sociales que, en principio, por el lugar que ocupaban en las relaciones de producción quedarían claramente enfrentados a las clases dominantes. Esto implica la multiplicidad de intervenciones tanto de los aparatos puramente estatales, como de los no estatales, para garantizar que este proceso no se rompa y que se autorreproduzca a pesar del evidente desequilibrio manifiesto que este sistema comporta ${ }^{26}$.

(26) Permítasenos señalar que uno de los temas más críticos y controvertidos en el análisis contemporáneo sobre los procesos de mediación es el de la integración política de clases y estatos generados o movilizados por la plena evolución hacia un modo de producción capitalista $\mathrm{y}$, asimismo, de los problemas interpretativos generados para entender cuál es el papel de aquellos otros grupos o fracciones de clase (singularmente el campesinado) que aparentemente permanecen al margen de lo que se ha llamado procesos de modernización, entendidos como la disolución de las relaciones sociales precapitalistas o -tradicionales. y la creación de otras capitalistas o -modernas.

Éfectivamente, el grado de integración social y política de las clases subalternas dependen de toda una serie de factores marcados por la propia evolución del bloque social de dominación o de dirección, por el grado de profundización y desarrollo del modo 
Ya hemos tenido oportunidad de señalar anteriormente algunas cuestiones sobre la República como un Estado liberalmente represivo y, cómo el cambio de sistema político no llevó consigo una modificación radical del sistema de poder. Hay que advertir que aunque nos estemos ciñendo, exclusivamente, al espacio específico de las comunidades rurales del sur peninsular, partimos del hecho cierto de que unas elecciones en el mundo agrario tienen tanta riqueza de componentes sociales y políticos como esos mismos procesos en las ciudades, tanto más si cabe advertir esto puesto que la mayor parte de la sociología electoral producida sobre la II República, hasta ahora en nuestro país, se ha circunscrito sobre todo al mundo urbano.

de producción dominante, por la articulación, pues, de los recursos sistémicos (toda una serie de factores ambientales -reales o potenciales- cuya combinación pueden ofrecer distintas posibilidades y expresiones de la lucha de clases. Pueden destacarse los recursos económicos, coercitivos y culturales; cf. R. BENDIX: Construcción nacional y ciudadanía., en Clase, status y poder. Madrid, Foessa-Euroamérica, 1972, pp. 88-89).

Como Göran THERBORN (¿Cómo domina la clase dominante?. Aparatos de estado y poder estatal en el feudalismo, el capitalismo y el socialismo. Madrid, Siglo XXI editores, $1987,3^{2}$ ed.) señala desde la perspectiva de los intereses de la clase dominante, la mediación del Estado en las relaciones entre la clase dominante y las clases dominadas debe lograr que estas uiltimas se sometan al orden social establecido y contribuyan a su funcionamientow. Efectivamente, esta definición entiende que la mediación no quiere decir, en este contexto, arbitraje, sino ejercicio del poder de clase a través del Estado. Recordemos cómo la unidad histórica de las clases dirigentes se produce en el Estado (proceso continuo inacabado), y la historia de esas clases es esencialmente la historia de los Estados y de los grupos de Estados, unidad que no es puramente jurídica y política, sino sobretodo histórica dando como resultado unas relaciones orgánicas entre el Estado (sociedad política) y la sociedad civil. (dlucha de clases?). Su esencial carácter es, por tanto, de clase aunque en determinados formatos de representación quede disumulado o diluido este componente, carácter en el que se inscriben una serie de aparatos materiales de promulgación, aplicación, judicación e imposición de leyes; y, también, por los mecanismos de reproducción de la clase dominante, que delimitan el radio de la intervención del Estado. Este no es nunca un mediador pasivo y neutral en la lucha de clases, sino que vincula a las mencionadas clases mediante una relación asimétrica de dominación y explotación. Esta relación es siempre dialéctica, la as̀imetría no implica unilaterialidad y unidireccionalidad, sino una serie de corrientes de piotesta/ sumisión, concesión/represión, etc.

De la misma manera, parece asimismo importante destacar que tales procesos de mediación son posibles contemplando una premisa: el deseo o la predisposición de las clases dominadas a ser cooptadas, lo que implica, en cierta medida, que no se opongan al orden social capi alista, dado que la total disidencia haría imposible la cooptación política. Esto implica conciencia de ser sujetos pasivos de la cooptación y, en consecuencia, una forma de adaptación para seguir perpetuando la reproducción social. Asismismo, se acepta que el mecanismo político más eficaz a través del cual se realiza la cooptación es el corporativismo, esto es, un sistema de representación de intereses -en el contexto de una sociedad capitalista- en el que las organizaciones representativas son autorizadas y reconocidas por el Estado que les otorga y las legitima para un deliberado monopolio de la representación, a cambio de aceptar ciertas reglas y exigencias. 
Centrándonos en el tema que nos ocupa, tanto Paul PRESTON como Eduardo SEVILLA ${ }^{27}$ han puesto de manifiesto cómo, en gran medida, la cooptación sobre el campesinado «sin tierra", durante la Segunda Repúbli$\mathrm{ca}$, hubo de tornarse en formas violentas. Ellos mismos han demostrado; en los trabajos citados, que la mayor parte de las comunidades rurales del sur de España presentaban una estratificación social tan desequilibrada y su grado de integración social era tan bajo que la presencia de los propagandistas del partido del orden (terminología que acuñamos para definir a las derechas en su conjunto) era insuficiente aval para convencer a las clases subordinadas campesinas de la necesidad de votarles.

¿Cómo se produjo la cooptación, en las comunidades rurales, durante el período de elecciones? ¿Dónde se pudieron producir acciones violentas por parte de las aclases de servicio tanto privadas como institucionales, sobre los jornaleros y sus familias? ¿Cuándo funcionó este sistema de mediación/dominación? Hemos de volver a señalar, una vez más, la importancia de la concepción del sistema de dominación local de clase que generó el latifundismo o los sistemas de explotación campesina subordinados a éste. Las manifestaciones externas de esta dominación recuerdan, por supuesto, lo que se ha dado en llamar caciquismo, patronazgo, clientelismo, etc. ${ }^{28}$ El sistema de Cortijos y Casas Grandes que se

(27) Un trabajo común en .Dominación de clase y modos de cooptación del campesinado en España: La Segunda República. en Agricultura y Sociedad, n² 3, Madrid (1977), pp. 147-164. De PRESTON: -La guerra agraria en el Sur. en Revolución y guerra en España, 1931-1939. Madrid, Alianza editorial, 1984, pp. 141-157; La destrucción de la democracia en España. Reacción, reforma y revolución en la Segunda Repuiblica. Madrid, Turner, 1978. Y de Eduardo SEVILLA: -Estructura de clases en una comunidad campesina latifundista., en Andalucía contemporánea (siglos XIX y XX) Córdoba, Publicaciones del Monte de Piedad y Caja de Ahorros de Córdoba, 1979, pp. 467-81.

(28) Aunque existe una cierta propensión por parte de todos los que tratamos estós temas a mezclar todos y cada uno de estos términos (clientelismo, patronazgo, caciquismo) existen francas diferencias, no sólo en la interpretación o utilización de cada uno de estos términos, sino, sobre todo en las teorías y análisis enfrentados entre estructuralfuncionalistas, individualistas metodológicos, críticos radicales del antropologismo clásico y marxistas (cf. Paul LITTLEWOOD: .Campesinos, producción' y patronazgo: un marco alternativo para analizar la relación patrón-cliente. en las sociedades campesinas mediterráneas, en Agricultura y Sociedad n 13, Madrid (1979), pp. 113-176, nos remitimos a la bibliografía que cita para evitar repetirla aquî. Y, por fin, sólo queremos citar algunas obras de interés que relacionan estos fenómenos en el contexto de las sociedades rurales y su relación con el control de la tierra (fuente generadora de recursos sistémicos) y todo lo que ello genera: Antonio SEGUI: .Sobre el sistema de patronazgo: Estudio realizado en una comunidad española., en Revista española de Opinión Püblica, n 46, oct-dic (1976), pp. 141-163; la producción de J.A. DURAN: Historia de caciques, bandos e ideologias en la Galicia no Urbana (Rianxo, 19101914). y Agrarismo y movilización campesina en el Pais Gallego (1875-1902). Madrid, ambos en S. XXI editores, 1972 y 1977. y, por fin, Ernest GELLNER (et alii): Patronos y clientes... Madrid, Júcar Universidad, 1985. 
extendían a lo largo de la geografía andaluza generaban una serie de relaciones sociales y laborales muy peculiares entre los grandes y medianos propietarios o sus administradores y encargados, y el resto de los trabajadores ya fueran fijos o eventuales, al margen por supuesto -en muchísimas ocasiones- de la propia legislación social agraria republicana. Las redes clientelares que se cuajaron en torno al juego del favor, el nepotismo, al reparto de esferas de poder tanto en administraciones provinciales, como locales, etc., vinieron marcadas -en las comunidades rurales- por la concentración de la propiedad de la tierra en muy pocas manos, por las formas de explotación de la misma, o por la subordinación del emodo de producción campesino" al latifundismo. Las relaciones verticales (a distintas escalas) u horizontales establecidas en torno al grado de apropiación de la tierra y a las posibilidades de acceso a los medios de vida, continuamos insistiendo, marcaron la actividad política y social en esas comunidades. ¿Quiere esto decir que la República no significó ningún cambio, tanto en materia electoral como social? ¿Es que las nuevas medidas (Ley de Términos, Laboreo Forzoso, Reforma Agraria, etc.) no pudieron romper o resquebrajar los círculos de la dominación/ subordinación y del favor/deferencia? En absoluto, más bien todo lo contrario. Sin embargo, conviene desmitificar la democracia republicana, no sólo porque las capacidades reales de manifestar libremente el voto o la opinión estuvieron especialmente limitadas durante el período de gobierno de populares, agrarios y radicales; sino porque la propia legislación social-agraria (por tan sólo mencionar dos temas del máximo interés) no alteró sustancialmente el carácter privado de la tierra, e incluso la monopolización de ésta (se podría decir que la legislación contempló el carácter social de la tierra, y que la Reforma agraria especificó la expropiación de los latifundios -con indemnización dicho sea de paso-, pero lo ambiguo de lo primero y lo transaccional de lo segundo, así como la lentitud en su ejecución marcaron buena parte del fracaso); a esto cabría añadir que, la implantación de esa legislación chocó con no pocas dificultades adicionales, entre las que se encontraban: el poder y la capacidad de control que muchas :clases de servicio* privadas ejercieron sobre ciertas capas del campesinado (renteros, administradores, manijeros, capataces, prestamistas, fiadores, etc.); $o$, en otras ocasiones, la falta de colaboracion de las eclases de servicio institucionales con la nueva administración central republicana (secretarios de ayuntamiento, guardias municipales, Guardia civil, etc.); pero, también, podrían incluirse otras cuestiones como !a capacidad de adaptación de los equipos políticos* de las antiguas oligarquías a la nueva situación, penetrando en los partidos republicanos de todo tipo (lerrouxistas, radical-socialistas, republicanodemócratas, liberales, conservadores, etc.) y, por supuesto, con la recu- 
peración por parte de las derechas de la inmensa mayoría de los ayuntamientos durante el •Bienio Negro• por el inveterado sistema de las Comisiones Gestoras ${ }^{29}$.

De las tres elecciones generales de Diputados a Cortes que se celebraron durante el período republicano, en al menos dos de ellas se manifestaron clara y palpablemente la violencia política y la cooptación institucional y privada sobre una parte muy considerable del campesinado, nos referimos a noviembre de 1933 y febrero de $1936^{30}$. Estas expresiones típicas de un proceso electoral coactivo, al que habría que dedicar mucho más tiempo del que en estos momentos disponemos, enlaza la pérdida de unas elecciones por parte de las clases dominantes con el grave y serio quebranto que esto les hubiera supuesto para seguir manteniendo su específico sistema de poder.

Sin embargo, la violencia no estuvo siempre presente como fenómeno generalizado, hubo otras fórmulas en las que la captación de adeptos y la canalización de voluntades se realizaron por métodos pacíficos, como fueron los de la cooptación propagandística-preventiva, entre las que seleccionamos la "cooptación político-católica. (importantísima en las elecciones de 1931 y 1933) y la cooptación relacionada con las formas de cultivo y explotación de la tierra. (más visible en 1936).

Refiriéndonos a aquélla, se trata de un proceso muy anterior a unas elecciones que requiere, por tanto, una amplia etapa de preparación y actuación, tanto de las instituciones gubernativas, como de las privadas. Los casos más típicos son la cooptación religiosa y la agrario-sindical. Para que éstas se cumplan, por lo general, se necesita crear un estado de opinión favorable que puede venir generado por un previo ataque. a la religión mediante un proceso de secularización de la sociedad civil, o una situación económica desfavorable para los sectores sociales que pueden ser fácilmente cooptados gracias a que una propaganda previa sobre estas capas sociales a sabido convencerles de su identificación de intereses y objetivos con los de otras fracciones de clase que se atribuyen la dirección del movimiento de protesta. Para poder culminar con un

(29) Véase Cuadró III del APENDICE.

(30) Cfr. la ponencia de José Manuel MACARRo VERA: La práctica política del socialismo andaluz en la II República. en Congreso sobre Historia de las organizaciones socialistas en Andalucia (1886-1975). 1 a 3 octubre de 1992 (en prensa); D. CARO CANCELA: La II Repuiblica en Cádiz. Elecciones y partidos politicos. Cádiz, Diputación Provincial, 1987; la comunicación presentada en este mismo Congreso por Paco COBO ROMERO: - Un República sin democracia. Elecciones y abúsos patronales. La cooptación política del campesinado jienniense en las elecciones del Frente Popular. y Mario LOPEZ MARTINEZ: El giro a la derecha. Elecciones Generales de 19 de Noviembre de 1933 en Granada. La cooptación política del campesinado. en V Congreso de Andalucismo Histórico, septiembre (1991) celebrado en Almería. 
cierto éxito este proceso es necesario reactivar toda una serie de instituciones creadas al efecto, tanto ciudadanas, como religiosas y sindicales, que consoliden una base social amplia de carácter populista y corporativista, en el que el principio de jerarquía está siempre presente, dando coherencia y cohesión al movimiento ${ }^{31}$.

De una parte esta cooptación político-católica de la que sólo daremos algunos detalles por ser muy conocida por este auditorio-, fue especialmente importante en Estados como el español, el peso de la *única. Iglesia existente fue sobresaliente en el desarrollo de las comunidades campesinas, fenómenos como el carlismo, el integrismo o el populismo católico, lo corroboran sobradamente. Con respecto a este último hay que señalar la consideración de la formación de una opción política católica asociada al contexto del establecimiento del sufragio universal masculino que fue la explicitación española del debate francés entre corporativistas y socialcatólicos versus liberales y cristiano-demócratas, debate suscitado por la apertura de la jerarquía eclesiástica concretamente de LEON XIII a finales del siglo XIX-, con las alusiones papales a "el pueblo* en la *Rerum Novarum* de 1891, suponiendo una superación de la postura rígida de la "Oratio super populum" que PIO IX, que había desautorizado las corrientes que buscaban la adaptación al Estado liberal por medio de la participación civil y electoral de los católicos ${ }^{32}$. La proyección de este populismo católico se fue explicitando en la formación de partidos políticos decididamente confesionales, sindicatos agrarios dirigidos por miembros de la jerarquía eclesiástica y organizaciones de carácter propagandístico y apologético dependientes de las directrices y la doctrina social de la Iglesia ${ }^{33}$, todas ellas formaciones de

(31) Véase la construcción del universo conservador por parte de las derechas españolas en nuestro trabajo L. ALVAREZ REY: La derecha en Sevilla durante la II Repuiblica..., pp. 344 y ss. Así como las obras de Esperanza YLLAN CALDERON: .Cánovas y los orígenes ideológicos de la Restauración., en Revista Internacional de Sociología, $\mathrm{n}^{\mathbf{2} 43}$, Madrid (1985), pp. 509-525; Javier JIMENEZ CAMPO: El fascismo en la crisis de la II Repuiblica. Madrid, C.I.S., 1979 y José Ramón MONTERO GIBERT: La CEDA. El catolicismo social y politico en la II República. Madrid, Revista de Trabajo, 1977.

(32) Cf. Enric UCELAY DA CAL: -Acerca del concepto "populismo.., en Historia Social, $\mathrm{n}^{\propto} 2$, Valencia (1988), p. 52.

(33) Cf. J. TUSELL y J. AVILES: La derecha española contemporánea. Sus orígenes: el maurismo. Madrid, Espasa Calpe, 1986; Ramón PUNSET: -Maura y el maurismo. Perspectiva histórica de la revolución desde arriba, en Sistema, $n^{2} 33$, Madrid (1979), pp. 129-141; Oscar ALZAGA: La primera democracia cristiana en España. Barcelona, Ariel, 1973; J. TUSELL: Historia de la democracia cristiana en España. I. Los antecedentes. La CEDA y la II República Madrid, Edicusa, 1974, entre otros.

Y, sobre la manera de organizar a las .clases populares, cf. J.J. CASTILLO: El sindicalismo amarillo en España. A drid, Edicusa, 1977; del mismo autor: Propietarios muy pobres. Sobre la subordinaci: ; polútica del pequeño campesinado: la Confederación 
muy diversa importancia y consideración, pero que jugaron un papel destacado en la formación de una amplia masa de opinión favorable a una dirección política y moral guiada exclusivamente por los dictados de la Iglesia católica ${ }^{34}$.

La cooptación política del campesinado con tierra", durante la Segunda República respondió, en buena medida, a la necesidad de crear un partido de masas formado por amplios sectores del campesinado pequeño propietario y arrendatario que, en hábiles formatos de representación, identificasen sus intereses con los de los grandes propietarios rurales bajo principios como: la conservación de la propiedad, la jerarquización de la sociedad y del trabajo, la perpetuación de los ideales católicos de moralidad y orden social, etc. En buena parte, el terreno quedó abonado por la propia estratificación social desigual en los rorígenes de la formación' del campesinado. de la Península Ibérica. Las múltiples comunidades rurales creadas, con distinto tipo de asentamiento ecológico y fuertes diferencias culturales, tenían en el caso de las sociedades campesinas un relativo grado de integración social. Esto se tradujo, políticamente, durante los períodos de tormenta social -como fue el caso del "trienio bolchevique* o la República-, en la necesidad por parte de los sintereses agrarios. de crear formaciones sindicales, políticas o propagandísticas que aunasen y cohesionasen supuestos intereses comunes entre los dispares elementos de la producción ${ }^{35}$.

Asimismo, el terreno quedó preparado para el cultivo de toda una reacción a la política de secularización del Estado incluida en el programa social-reformista que, aceleró, en algunos casos esa alianza entre sectores del campesinado y las oligarquías provinciales. Cuestiones como la no confesionalidad del Estado, la introducción del matrimonio civil y del divorcio, la institución de un sistema educativo secular inspirado en

Católica Agraria, 1917-1942. Madrid, Ministerio de Agricultura, 1979; Josefina CUESTA BUSTILLO: Sindicalisma católico agrario en España (1917-1919). Madrid, Narcea, 1978; J. SANCHEZ JIMENEZ: Sindicalismo católico agrario en Andalucía, en Revista dé Estudios Sociales, $\mathrm{n}^{2}$ 17-18, Madrid (1976), pp. 75-100; J. ANDRES GALLEGO: El movimiento agrario confesional de principios de siglo XX, en Hispania. Revista española de bistoria $n^{2}$ 147, Madrid (1981), pp. 155-195 y J.J. CASTILLO: .Modulaciones ideológicas del catolicismo social en España: de los Círculos a los Sindicatos, en Revista Española de Opinión Pública $n^{\circ}$ i45, Madrid (1976), pp. 37-75.

(34) Cfr. J. ANDRES GALLEGO: La política religiosa en España, 1889-1913, Madrid, Editora Nacional, 1975; de este mismo autor: Pensamiento y acción social de la Iglesia. en España, Madrid, Fipasa-Calpe, 1984; D. BENAVIDES GOMEZ: Democracia y cristianismo en la España de la Restauración, 1875-1931, Madrid, Editora Nacional, 1978, de este mismo: El fracaso social del catolicismo español: Arboleya Martinez, 1870-1951, Barcelona, Nova Terra, 1973 y F. MONTERO GARCIA: El primer catolicismo social y la -Rerum Novarum en España (1889 1902), Madrid, CSIC, 1983.

(35) Véase la nota 33. 
el ideal de solidaridad humana ("Escuela unitarian), la retirada de los símbolos religiosos de las escuelas, la auto-financiación del clero, la disolución de la Compañía de Jesús y la prohibición expresa de cualquier intervención de los religiosos en la industria, el comercio y la educación fueron una ruptura lo suficientemente importante para que se argumentase la necesidad de una unión moral de todos los católicos frente al nuevo Estado y alimentó y consolidó, en algunos casos, el aautoritarismo rural tradicional. El éxito o fracaso de esta propaganda -profusamente alimentada desde Arzobispados, Obispados y demás redes o agencias de agitación ${ }^{36}$ - sólo podrá ser en parte virtualmente examinado con la consulta de nuevas fuentes como los papeles *Ad Líminaw.

$\mathrm{Y}$, en cuanto a cooptación y explotación de la tierra podemos señalar, también, algunas ideas servidas para la discusión en este foro. El trigo reflejaba como pocos cultivos -aunque podríamos incluir en cierta medida al olivo, la vid, y algunos productos agrícolas subtropicales (caña de azú-

(36) Sin duda alguna una de las mejores y más exitosas de las movilizaciones realizadas por los voceros social-católicos fue la propaganda desplegada entre el campesinado de la provincia de Granada en protesta contra la Ley de Congregaciones Religiosas, desde febrero hasta mayo de 1933, se pusieron en marcha todas las formas pacíficas con que contaban los elementos del ppartido del orden: hojas volantes, cuñas publicitarias en periódicos, mítines, misas de campaña, telegramas a los poderes públicos, discursos en los púlpitos, en los salones sociales, en los ayuntamientos, etc. Más de una docena de organizaciones defensoras de los intereses espirituales y terrenales de la Iglesia católica respaldaron dichos trabajos: la Federación de Estudiantes Católicos, la Obra Defensa de la Fe, la Archicofradía del Perpetuo Socorro, la Asociación del Corazón Eucarístico, los Sindicatos Católicos del Ave María, las distintas Cofradías y sus directivas, la Asociaciación Femenina de Eduación ciudadana, Acción Obrerista, la Adoración Nocturna, los socios mayores del Consejo de Conferencias, las Hijas de María del Sagrado Corazón, la Asociación Madre y Señoras Cristianas, la Juventud Católica Femenina, la Agrupación Femenina Tradicionalista, la Asociación Católica de Padres de Familia, el Apostolado de la Oración, el Centro y Talleres de .Santa Rita de Casia y el Pueblo Cristiano., la Acción Católica de la Mujer, la Acción Católica Masculina, etc. Cfr. Archivo del Congreso de los Diputados: .Negociado de proyectos de ley (1931-1933), leg. $\mathrm{n}^{\mathrm{s}} \mathrm{S} 534$ y 535 , exp. 1 (telegramas de Granada, Guadix y Caniles). Este último decía: Los que suscriben, vecinos de la Villa de Caniles y en representación de las Hermandades que presiden, tiene el alto honor de dirigirse a S.E. y con todo respeto SUPLICAN: Que al tratar en las Cortes de su digna presidencia del proyecto de CONGREGACIONES RELIGIOSAS, lo bagan desapasionadamente teniendo en cuenta los beneficios que reportan a la nación en todos los órdenes y sobre todo en social y educativo. (17-II-1933) y estaba firmado por los presidentes y presidentas de las siguientes asociaciaciones: -Ntra. Sra. del Rosario*, „Purísima Concepción., "Ntr Sr. Crucificado, . Orden Tercera", "Apostolado de la Oración, .Ntr ${ }^{2}$ Sra. de los Dolores, .San Antonio de Padua., .Ntr' Sra. del Carmen., *Ani-

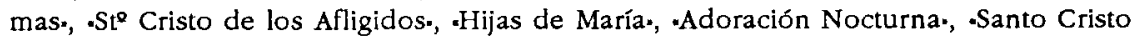
del Solar., :Hora Santa., .Ntr Padre Jesús. y .San José. '

Lo mismo se podría decir de otras provincias estudiadas en este sentido como la de Sevilla. Cf. Mario LOPEZ MARTINEZ: Elecciones, caciques y campesinos..., pp. 160 y ss. y Leandro ALVAREZ REY: La derecha en Sevilla..., p. 344. 
car en la Costa granadina)-, la materialización específica y peculiar del desarrollo del capitalismo agrario en la formación social hispana. Del mismo modo, siguiendo en este terreno, la acción del Estado fue adquiriendo un peso cada vez más decisivo en la determinación de los precios del cereal, y de la expansión o reducción de la superficie sembrada. Una intervención política liga da estrechamente a la vida histórica de las instituciones liberales o, incluso mejor, de la propia configuración del bloque social dominante. De manera que, el sistema triguero español y la oligarquía agraria formaban un tándem indisoluble que se autorreproducía constantemente con la aplicación de continuos aranceles proteccionistas. La crisis agraria finisecular reforzó las contradicciones del sistema productivo agrario en sus implicaciones no sólo económicas y sociales, sino también políticas. A nadie se le escapa que los precios del cereal fueron el resultado de complejos procesos y manipulaciones político-administrativas que precisaban atender: desde precios de garantía, hasta los derechos de protección aduanera, los impuestos..., etc., en los que las proyecciones ideológicas sobre el cultivo del cereal como expresión de los intereses contradictorios de distintas clases y fracciones se convertían en un arma más de combate. Como señala Alfonso ORTI: «los sistemas de cultivo materializan ideologías, las reproducen de forma ampliada, las fijan $-y$ a veces las estancan-, para volver a condicionar la lucha política y a realimentar sus enfrentamientos ideológicos ${ }^{37}$. La 'plataforma triguera castellana. -tal como la denominó el profesor Nicolás SANCHEZ-ALBORNOZZ ${ }^{38}$ - era el fruto de la convergencia de los intereses de la gran propiedad agraria (latifundistas) y del capitalismo especulativo (-los acaparadores de granos.), sin olvidar tampoco en esta tramoya, por supuesto, el papel subordinado del pequeño-campesinado parcelario y el impacto del desarrollo capitalista de «tipo semicolonialu tanto en el vasto proletariado agrícola, como entre las masas populares urbanas que habían de soportar la crónica subalimentación por mor de la política proteccionista. Pero, es más, el mayor peligro, tanto electoral, como político -desde la perspectiva republicana y progresistaconsistía en que la alternativa proteccionista al desarrollo del capitalismo agrario español concluyese por arrojar al campesinado en los brazos de una alianza reaccionaria formada entre otros por la gran propiedad cerealera y latifundista. En este último punto radica gran parte de los procesos de cooptación durante el seríodo de los años 30 , la alternativa para el campe-

(37) -Dictámenes y discurso: de Joaquín Costa en los Congresos de Agricultores y Ganaderos de 1880 y 1881 . (Oríge. es de la política hidráulica: la polémica del cereal español en la crisis agraria de los años 1880)., en Agricultura y Sociedad, n 1, oct-nov. (1976), p. 212.

(38) En -Castilla * el siglo XIX: una involución económica., en Revista de Occidente, $\mathrm{n}^{\circ} 17$, Madri 1982), pp. 35-49 y Castilla. El neoarcaismo agrario, 1830-1930, en La modernización económica de Espäña, 1830-1930. Madrid, Alianza Universidad, 1985, pp. 287-298. 
sinado era francamente dolorosa: o proteccionismo a ultranza y, por tanto, lucha contra la ciudad republicana, o ruina y miseria total ante la liberalización comercial en condiciones de crisis económica internacional y pequeñas explotaciones agrarias atrasadas y estancadas.

Los terratenientes supieron situar el ojo del huracán en la dirección adecuada, sus poderosas asociaciones ${ }^{39}$ : tanto la Unión Agraria, como la Confederación Nacional Católico-Agraria emprendieron, en 1932, una campaña en favor de la subida de las tasas del trigo, aunque si bien hay que considerar que en economías de escala esto beneficiaba claramente a los grandes propietarios, los pequeños productores no podían situarse sino con aquellos que defendían la mencionada subida pues su fuerte dependencia del mercado y su especialización les abocaban a un callejón sin salida. Sobre los éxitos de esta campaña triguera de la Minoría Agraria para desprestigiar al ministro de Agricultura Marcelino DOMINGO tenemos análisis ciertamente interesantes ${ }^{40}$. El final de todo este asunto culminó con la importación de trigo y la aparición en el mercado -icómo por arte de magia!- de un gran contingente de granos almacenados hábidos de rápido beneficio. Sin embargo, aunque conocemos las importantes repercusiones de este fenómeno en las elecciones de noviembre de 1933, cuya expresión decantó muchos votos hacia las derechas, seguimos sin tener estudios provinciales que entren en detalles. Lo más interesante, sin embargo, no termina aquí, la política triguera de las derechas en el poder y la legislación promulgada permitieron un cierto control del mercado y la expedición de licencias por parte de las asociaciones agrarias patronales lo que abrió enormes expectativas para la reconstrucción de los sistemas de favor y dominación de clase. No cabe extendernos más sobre algunas de estas cuestiones, aunque hay que seguir señalando la importancia de fenómenos como los que acabamos de apuntar ${ }^{41}$.

Sin embargo, en muchas ocasiones, la cooptación a la cual nos estamos refiriendo se mostró totalmente insuficiente para actuar como *canalización preventiva. del conjunto de la sociedad, o de aquellos sectores sociales hacia la que iba dirigida, dada la complejidad y variedad de las fracciones de clase y de sus propias producciones ideológicas y sociales. Tal complejidad, en ocasiones, no permite esa pretendida uniformización política $\mathrm{y}$, por tanto, ciertos planteamientos populistas, jerárquicos y demagógicos sobre la que se basa una cierta propaganda chirrían por

(39) Cf. Mercedes CABRERA: La patronal ante la II Repiblica. Organizaciones y estrategia, 1931-1936. Madrid, Siglo XXI editores, 1983, pp. 60-79.

(40) Véase, P. PRESTON: La destrucción de la democracia..., PP. 70-72; E. SEVILLA: La evolución del campesinado..., pp. 97 y ss.; Mercedes CABRERA: La patronal ante la II Repüblica..., pp. 107-115.

(41) Cf. M.L.M.: Elecciones, caciques y campesinos..., pp. 173-188. 
fuerza. En esta tesitura, existe una necesidad de reactivar, por otros mecanismos, los procesos de mediación, bien a través del Estado o de aparatos no estatales. Dicho de otra manera, ya no son los aparatos ideológicos del Estado los que pueden actuar eficazmente, sino que son los represivos $y$, por tanto, la violencia la que hace su aparición, con más frecuencia durante la República -todo hay que decirlo- de lo que se sospecha.

Por tratar de resumir y analizar tres fueron los bloques de medidas que intervinieron en los procesos electorales durante la II República: toda una serie de medidas preventivas institucionales, sociales y de Orden público (inos recuerdan a períodos anteriores?); otras que de alguna forma institucionalizaban el fraude y, por último, la violencia electoral abierta.

Las medidas preventivas estaban destinadas a asegurar y facilitar un proceso electoral favorable al gobierno, entre sus disposiciones institucionales estuvieron los cambios de corporaciones municipales por Comisiones Gestoras afines (Elecciones Municipales parciales de Mayo de 1931 y Elecciones Generales a Cortes de febrero de 1936) o la destitución temporal de determinados agentes y autoridades locales que estorbasen a aquellos intereses (Elecciones Generales de Noviembre de 1933) ${ }^{42}$. Entre las intervenciones sociales se hallaron la derogación de la polémica Ley de Términos Municipales, elaboraciones paralelas de Bolsas de Contratación y todo tipo de coacciones económicas -cambio de contratos de arrendamiento, despidos libres, etc- (Elecciones de 1933 y 1936) ${ }^{43}$. Y, por último,

(42) Durante las elecciones de noviembre de 1933, los miembros de los comités locales de algunas formaciones políticas del -partido del orden- pidieron y exigieron a algunos líderes de importancia como fue el caso de Alejandro LERROUX, la destitución previa de Ayuntamientos en manos de republicanos y socialistas antes de comenzar el proceso electoral, con el fin de asegurarse la victoria en las elecciones [Carta de A. LERROUX a Rafael TORRES DURAN (24-X-1933), en Fundación Pablo Iglesias (Archivo Histórico): leg. 24-5]. En 1933, no se destituyeron ayuntamientos, pero sí que se abrió, desde septiembre de ese año un proceso de acoso y de preparación de la opinión pública en contra de esas administraciones. Durante las elecciones de 1936, sí que se cambiaron algunas Comisiones Gestoras para garantizar el triunfo de la candidatura del :Bloque Nacional, se instalaron comités políticos progresistas que prepararon por fidelidad al Gobierno la victoria de aquélla [El Defensor (7 y 10-I-1936 e Ideal (3, 4 y 10-I-1936]. Las medidas se extendieron a la destitución de clases de servicio no afectas, como la renovación extraordinaria de Juzgados municipales en agosto de 1934, la destitución de guardias municipales que habían colaborado estrechamente con los grupos de derechas, etc.

(43) Para las elecciones de 1933, se suprimieron las fronteras municipales en toda la provincia de Granada, justamente, un mes antes de celebrarse los comicios [Ideal (8-X-1933)]. La importancia de esta medida fue fundamental para amedrentar al campesinado sin tierra y conseguir una atmósfera de resignación entre sus familias. Esta medida dio pie a la vuelta al sistema represivo de selección de mano de obra, así como a la confección de bolsas paralelas de contratación en todos aquellos pueblos con sindicatos agrícolas de tutelaje patronal con fuerza para hacerlo' y con Ayuntamientos de derechas; las 
la libre actuación gubernativa a través de instrumentos como los Gobernadores civiles, los delegados gubernativos y la Guardia civil hicieron el resto en materia de Orden Público: el aumento de fuerzas de seguridad en los lugares de propaganda de las izquierdas o a las puertas de las Casas del Pueblo, el cierre de Centros de organización y resistencia del campesinado por motivos variopintos (sanitarios, administrativos, político-subversivos, etc.), el reparto discriminado de licencias de armas entre elementos de orden", el desarme de policías locales de Corporaciones municipales de izquierdas y los cacheos y registros preventivos tanto de personas como de entidades sociales progresistas (Elecciones Generales de 1933 y 1936) ${ }^{44}$.

quejas de las Sociedades Obreras no se hiceron esperar, muchas de ellas protestaron porque estas medidas doblegaron muchas voluntades por el thambre que doma. [Ideal (16 y 26-X-1933) y El Defensor (9, 10 y 11-X-1933)]. Para las elecciones de 1936, la dirección de muchos sindicatos y asociaciones patronales sobre el control del mercado y la oferta de trabajo era tan notable que la mayor parte de los campesinos/jornaleros que querían trabajar previamente a los días de elecciones tuvieron que asegurar que votaría a la candidatura de las derechas.

(44) Tanto durante las elecciones de 1933, como en la de 1936 hubo un aumento considerable de efectivos de la Guardia civil en la provincia de Granada [Diario de Sesiones de las Cortes: 15-XII-1933 y. 31-III-1936; El Socialista (16-XII-1933)]. Asimismo, las elecciones del Frente Popular se desarrollaron en un ambiente de tensión y una atmósfera de violencia marcada por el cierre continuado de Casas del Pueblo y de Sociedades Obreras desde octubre de 1934 [*:Por qué permanecen cerrados los Centros obreros en la provincia de Granada?. en El Defensor (11-XII-1935); y Fundación Pablo Iglesias (Archixo Histórico): 14-16, 14-18, 14-24, 14-25 y 14-26]. El cacheo continuo los días previos al de elecciones y el propio día de los comicios fue materia muy habitual, los obreros y campesinos socialistas y anarcosindicalistas se quejaron continuamente de ello, a veces aquéllos se convirtieron en actos violentos, con maltrato de obra, palizas, etc. [Arcbivo Histórico Nacional (Salamanca), P-S Madrid: carpeta $\mathrm{n}^{\circ} 230$ (1936) y Archivo del Congreso de los Diputados: leg. 141, exp. 20 y El Defensor (II-1936).]. El reparto de licencias de armas entre personal afecto a los partidos del orden fue muy peculiar tanto en 1933, y masivo en 1936, se reconstituyeron los antiguos somatenes armados en algunos pueblos (Güejar Sierra), bandas de escopeteros, pistoleros traidos de Madrid expresamente para atemorizar a la población, impidiendo salir o introducirse en el pueblo ningún tipo de apoderado o interventor de las izquierdas [Archivo de la Diputación Provincial: leg. 99 y 110; Archivo del Congreso de los Diputados: leg. 141, exp. 20; Archivo Histórico Nacional (Salamanca), S-P de Madrid: carpeta 230; -Documentación sobre la reclamación de los diputados electos del Partido Socialista al Excmo. Sr. Presidente de la Junta provincial del censo electoral (20-XI-1933)* en Archivo del Congreso de los Diputados: leg. 139, exp. 20]. Lógicamente esta medida se tomó en detrimento de otras fuerzas que podrían estar controladas por los ayuntamientos, en 1933, en manos de socialistas o republicanos de izquierdas, para ello el Gobierno civil de la provincia ordenó el desarme de todos los guardias municipales, claro está, de aquellas corporaciones de izquierdas, asumiendo la Guardia civil esas funciones [Telegrama al $M^{\mathbb{P}}$ de Gobernación y al director de EL SOCIALISTA (18-XI-1933) en Archivo Histórico Nacional (Madrid), Gobernación Serie A: leg. 31 A, exp.6; y, quejas de los alcaldes de los pueblos de Puebla de Don Fadrique (18-XI-1933) y Guadix (19-XI-1933) en Ibidem: leg. $31 \mathrm{~A}$, exp. 6; y el pueblo de Iznalloz en Fundación Pablo Iglesias (Archivo Histórico): .Elecciones de 1933 en Granada", leg. 24-5.] 
Consecuencia de todos los procesos antes mencionados llevó -en determinados pueblos en connivencia con los Gobernadores civiles- consigo una cierta institucionalización del fraude. poniendo trabas administrativas para la confección de los Censos.o de las Mesas electorales, deflación del Censo en las zonas residenciales o inflación en los barrios obreros, actas electorales en blanco, escrutinios fuera de los Colegios electorales, etc. ${ }^{45}$

Evidentemente, esta suerte de detalles para el fraude no se pudieron realizar -en muchas ocasiones- sin recurrir a la violencia electoral institucional. El ejemplo de Granada en febrero de 1936 es más que paradigmático: palizas a Presidentes de Mesas que se negaban a tergiversar los recuentos, amenazas y coacciones a apoderados e interventores socialistas y republicanos azañistas, bandas de escopeteros pagados por el Partido Agrario que obligaban a quedarse en sus casas a los líderes campesinos so pretexto de no poder garantizar su integridad física, detención y secuestro -durante el día de elección- de varios notarios para que no pudieran dar fe de lo que sucedía en los pueblos durante las elecciones, atentados frustrados contra algunos líderes sindicales y políticos de izquierdas, $\operatorname{etc}^{46}$. ¿Sucedió lo mismo, aunque en escala

(45) En las elecciones de 1933, al menos en tres ocasiones el jefe del Partido Republicano Radical de Granada (PAREJA YEVENES) visitó al Gobernador civil de la provincia, las conversaciones no trascendieron en absoluto, pero es de presumir -y no son meras especulaciones- que se trataron los temas de: formación de una única candidatura antimarxista., para la concentración de tropas de la Guardia civil y para la adopción de medidas encaminadas a garantizar el control arbitrario de las elecciones [El Defensor (20, 25 y 28-X-1933)]. El propio secretario provincial del Partido Radical envió circulares a los presidentes de los comités locales brindándoles el respaldo de tropas de ese Instituto y el envío de delegados gubernativos [Arcbivo del Congreso de los Diputados: leg. 139, exp. 20; Fundación Pablo Iglesias (Arcbivo Histórico): -Elecciones de 1933 en Granada. leg. 24-5 y El Socialista (12-XI-1933).].

(46) Seleccionamos a continuación algunos datos sobre tres comarcas de la provincia de Granada, durante las elecciones de febrero de 1936: Hoya de Guadix, Altiplanicie de Huéscar y Costa:

En Alcudia de Guadixi el alcalde-gestor, además de detener a varios apoderados (Pérez Montero y Vela), junto a varios escopeteros se resistió a que los candidatos y el notario visitaran los colegios y expulsó por la fuerza, bajo amenazas de muerte, a apóderados e interventores. En Beas de Guadix, los caciques rompieron la documentación y las urnas, aplazando la elección para cuando la convoque la superioridad. En Charcbes, la Guardia civil del puesto de Gor, en unión del cura, del alcalde, del recaudador de contribuciones y de otros elementos, todos empuñando pistolas, hicieron objeto de agresiones a los interventores del Frente Popular, cerrando el colegio a las tres de la tarde y expulsando violentamente del local al apoderado de Izquierda republicana. En Esfiliana, el presidente de la Mesa rechazó a los interventores y apoderados de izquierdas y un policía municipal arrebató y rompió los documentos acreditativos del apoderado Vázquez Ramirez. En Fonelas, el caso parece sacado de un esperpento valleinclanesco. El candidato Corro Moncho, junto a un notario, levantó acta del cierre de varios colegios antes de la hora legalmente prevista, señalándoles los presidentes de los mismos, el delegado gubernativo y el comandante de puesto de la Guardia civil que sus relojes estaban atrasados. Igualmente en Lugros, los 


\section{ALGUNAS SUGERENCIAS FINALES Y APUNTES SOBRE LAS FUENTES}

Hemos de ir concluyendo algunos aspectos de interés que no queremos dejar de apuntalar en esta charla: estas cuestiones, entiéndase, son sólo unas notas y consideraciones, abiertas lógicamente a la discusión, de ciertos fenómenos que en la mayor parte de las investigaciones sobre sociología electoral en Andalucía, haciendo las convenientes excepciones

colegios se cerraron antes de la hora legal. Y, el mismo caso sucedió en La Peza, sólo que en este lugar intervinieron coaccionando y adelantando el cierre la propia Guardia civil acompañada de guardas jurados según acta notarial. En concreto, sobre las tres de la tarde, fueron retiradas las urnas y cerrados tres colegios electorales, correspondientes a tres secciones del distrito primero, información que fue facilitada mediante acta notarial. Además, en esta misma localidad, los interventores de izquierdas denunciaron que fueron obligados, por la presión de la Guardia civil y los guardas jurados, a firmar las actas electorales en las que se había establecido la mayoría para las derechas.

En Castilléjar, el apoderado Manuel Enrique Navarro fue encarcelado, sin motivo legal, el día 15 y puesto en libertad el 16 por la tarde. En Castril, en una de sus secciones votaron individuos que no estaban inscritos en el censo. En Huéscar, el candidato de Unión Republicana, Martínez Jerez, y los apoderados, junto al notario de la localidad fueron amenazados por el cabo de la guardia civil y por uno de los guardias municipales del pueblo, deteniéndoles y encerrándoles por unas horas en el Ayuntamiento. $Y$ en varios anejos de la Puebla de Don Fadrique, varios electores realizaban compras de votos y coacciones a los electores que se acercaban a las Mesas.

Cfr. Archivo Diputación Provincial de Granada: leg. 105 y 107. Arcbivo Congreso de los Diputados: leg. 141, exp. 20. Y, A.H.N. (Salamanca): P-S Madrid carpeta $\mathrm{n}^{\circ} 230$.

Y la zona de la Costa:

En Almuñécar, varios presidentes de Mesas se negaron a dar certificados de constitución de las mismas a los representantes del Frente Popular; y, además, uno de los presidentes de Mesa (sección primera, distrito segundo) ordenó numerosas detenciones de apoderados e interventores de izquierdas.

En Gualchos (un anejo de Castell de Ferro) en una de sus secciones al comprobarse, por su presidente y los adjuntos, la mayoría de las izquierdas se negaron a firmar las actas hasta que éstas no fuesen revisadas por el delegado gubernativo, que determinó la expulsión del colegio de los apoderados de izquierdas, a los que se les golpeó a culatazos por la fuerza pública.

En Itrabo, el alcalde, acompañado de guardas de campo armados, dentro de los colegios examinaba las candidaturas para saber a quién iban a votar los campesinos, e incluso las mujeres, llegaban hasta la urna cogidas del brazo por electoreros.

En Molvizar, un apoderado del frente de izquierdas fue expulsado violentamente del pueblo.

Y, por fin, en Motril, se levantaron numerosas actas notariales. Varias Mesas electorales se constituyeron sólo con los presidentes, sin haber comparecido los adjuntos propietarios ni suplentes (algunos de ellos declararon que por haber sido amenazados). En algunas otras, se levantaron actas notariales (tres concretamente, elegidos por el notario al azar entre el total de colegios de Motril en la Junta municipal del Censo) en las que se demostraba que los presidentes de Mesa habían sido nombrados arbitrariamente, no a los que les correspon- 
que se quieran, no se han abordado con toda la profundidad que se deseara. En ningún caso los puntos que a continuación mencionaré tratan de ser conclusiones o indicaciones rigurosas, sino meras sugerencias o reflexiones:

Primera: Creo que será reconocido por todos los aquí presente el hecho de que tenemos un exacto conocimiento de cómo se celebraron las elecciones municipales de abril de 1931 en cuanto se refiere a detalles como: programas electorales, formación de candidaturas, celebración de mítines, e incluso con menos precisión de sus resultados... Sin embargo, sabemos muy poco o casi nada del complejo proceso político desarrollado inmediatamente con posterioridad a las Elecciones Generales Municipales, tanto de mayo de 1931, como de abril de 1933. Un ejemplo muy claro de ello se puede referir a la repetición de los comicios municipales en Mayo de 1931, haciendo un mero balance podemos advertir la importancia cuantitativa que tuvieron: en provincias como Granada se repitieron en el 69,6 por ciento de los pueblos; en Cádiz en el 60,9, y en Almería en el 75,5; en general, la media regional superó el 50 por ciento. Este hecho, nada más, nos debe de poner en guardia sobre el cierto vacío historiográfico en esta materia.

día, sino a personas de fácil manejo. También, un buen número de interventores del Frente Popular fueron encarcelados el dia anterior para impedirles que ejercieran su cometido. En otra Mesa (sección primera distrito tercero), un apoderado de Acción Popular se llevó el acta de constitución impidiendo que se formalizaran las presentaciones de los miembros de los candidatos que representaban al bloque de izquierdas. En varias Mesas, los presidentes; coaccionados por el delegado gubernativo o por voluntad propia, cambiaron numerosas papeletas, permitieron que un solo elector votara en nombre de varios, etc. En una mesa (sección cuarta, distrito cuarto) concretamente, un gestor del Ayuntamiento abrió la urna y depositó un paquete con trescientas papeletas. También, la actuación de la fuerza pública fue decisiva en este cúmulo de irregularidades, ya que ésta denegó en varias ocasiones- el auxilio para proteger las actuaciones de varios apoderados del F.P., así como muchas de las gestiones que realizó el notario autorizante, Sr. Ortega Puga. Constaban en las actas notariales-, asimismo, las detenciones del candidato Narciso González Cervera y veinticinco apoderados, que fueron visitados en la cárcel por el notario. Así como diversos altercados protagonizados por elementos de las derechas juveniles al visitar, Fernando de los Ríos, la ciudad de Motril la noche del día 15, denuncias a las que se unió la del secretario de la Sociedad de Panaderos de la U.G.T. al manifestar que contra el ex-ministro socialista se preparaba un atentado que habría de ser perpetrado por tres pistoleros a sueldo pagados por Acción Popular que actuaban desde hacía varios meses en aquella ciudad.

Cfr. Esta documentación, especialmente la de Motril, está sacada de los detalles que aportan las actas notariales, actas electorales y protesta realizadas por las izquierdas. Víd. Archivo Diputación Provincial: legs. 112 y 143 (Telegrama de protesta: 17-II-1936). Y, A.H.N. (Salamanca): P-S Madrid, carpeta $n^{2} 230$.

(47) Para todo lo señalado nos remitimos a nuestro trabajo Elecciones, caciques y campestnos en Granada durante la II Repüblica.., pp. 137-153, 698-769 y 959-1.013. Además para el período electoral de Mayo de 1931 en nuestra monografía Granada (19301931). De La Dictadura a la República. Granada, Ignacio Llamas editor, 1990, pp. 181192 y $229-30$. 
Con ser esto cuantitativamente importante y significativo, no es lo más notorio. Lo destacable del asunto y, esta es una cuestión que tendrán que confirmar o desmentir las sucesivas investigaciones, son otros procesos paralelos a la convocatoria. Sigamos recurriendo a ejemplos que abren interesantes interrogantes. Según éstos, podríamos preguntarnos ¿cómo se desarrollaron las luchas políticas por la toma de los poderes locales en procesos tales como la formación de Comisiones Gestoras, encargadas de vigilar la pureza de los comicios repetidos en mayo? ¿O cómo se realizó el reajuste de fuerzas, con la proclamación de la República? ¿Cuál fue el comportamiento de muchas "clases locales de servicio" ante la nueva situación? O, por sólo abordar una pregunta más de las muchas que el investigador debe hacerse: ¿cuáles fueron los nuevos formatos de representación y explicitación del poder, lo que M. FOUCAULT denominó la ‘microfísica del poder", las redes capilares, etc.?. Esta dimensión parece imponer un "asalto* pacífico a los archivos municipales, así como la comparación minuciosa de las actas electorales de abril y mayo de 1931.

Segunda: A propósito de los resultados de las elecciones municipales, parece necesario descartar definitivamente como poco fiables los datos del *Anuario Estadístico de España, en todo caso de tenerlos en cuenta, sólo se pueden considerar como el resultado de sumar las concejalías de aquellos ayuntamientos de abril donde no se repitieron los comicios, junto a aquellos otros donde sí se celebraron. Lo que, de hecho, distorsiona la realidad política y electoral producida en Abril, y nos deja en un punto muerto de conocimiento el proceso de Mayo. En este sentido es conveniente seguir indagando en los datos oficiales, no sólo fuentes conocidas como el Archivo Histórico Nacional (Gobernación Serie A), la prensa o las actas electorales; sino archivos de ámbito estatal como el Histórico Nacional de Salamanca (Secciones Político-Sociales) o el del Ministerio de Gobernación, Palacio del Infantado recogido en el Archivo General de la Administración del Estado en Alcalá de Henares que ofrece no sólo datos pormenorizados y específicos de Abril y Mayo de 1931, sino que incluso incluye la evolución política de los ayuntamientos, al menos, hasta octubre de 1932. Sin duda, la combinación de todas estas fuentes, nos darían una información de primera mano para comprender la política municipal durante los cinco años de República en su relación directa con la aplicación de la legislación social-agraria y con las distintas fórmulas de expresión del conflicto campesino frente a los aparatos administrativos del Estado-nación; además de, por no dejar de señalar, la importancia del control de las corporaciones locales en el resultado de unas elecciones.

Tercera: Nos sentimos obligados a hacer una referencia a los comicios a Cortes Generales de noviembre de 1933. A nuestro juicio este proceso electoral requiere mayor atención de la que hasta ahora se ha prestado. 
Esto implica, no obstante, abordar al menos en el estricto ámbito de las comunidades rurales, algunas cuestiones como las que siguen: realizar un esbozo o estudio de la tipología y características de la conflictividad campesina generada durante el primer bienio; calibrar el alcance de la cooptación triguera, remolachera, etc., en las economías de escala; asimismo, valorar los efectos políticos de la diferenciación social interna en el seno del campesinado en relación con la aplicación de la Reforma y Leyes Agrarias; o, recoger el impacto propagandístico del catolicismo social entre los pequeños labradores y productores, por tan sólo mencionar algunas líneas posibles de investigación.

Por supuesto, somos conscientes que esto requiere la ampliación y el riguroso examen de muchos más datos de los tradicionalmente barajados para el estudio de unas elecciones. Creemos que una investigación no funcionalista* así lo requiere, puesto que estos temas señalados, junto a otros que están en la mente de todos configuran, con mayor exactitud, el sentido y la realidad del voto. Lógicamente, esta necesaria e imprescindible ampliación temática solicita nuevas fuentes: Ciertas actuaciones de los gobernadores civiles aparecen en sus expedientes personales en el *ArChivo del Ministerio del Interior. (allí se albergan los telegramas de protesta de muchas sociedades obreras y Casas del Pueblo, entre otras cosas)! Los censos de campesinos están en el IRYDA o en el Boletín del Instituto de Reforma Agraria dispuestos para ser consultados, ellos nos apuntan datos sobre la diferenciación social interna del campesinado; asimismo, el $* A r$ chivo del Congreso de los Diputados", creemos que está siendo francamente infrautilizado, así como el «Diario de Sesiones» que en sus páginas referidas a los trabajos de la Comisión para la revisión de Actas, recogen las más diversas tipologías del fraude, así como las discusiones sobre éste y datos del máximo interés sobre el grado de pureza de una consulta electoral; este mismo archivo recoge interesantísimas cuestiones sobre el alcance de la propaganda religiosa entre los campesinos (recogida de firmas y adhesiones contra la Ley de Congregaciones o contra los artículos secularizadores de la Constitución), propaganda sufragada por algunas diócesis andaluzas, en cuyos archivos pueden consultarse los documentos "AD LIMINA* sobre las dimensiones y profundidad de la religiosidad popular y oficial. También es imprescindible para conocer la documentación preparatoria de determinadas actas protestadas por la izquierda, la consulta del *Archivo Histórico. del PSOE en la Fundación Pablo Iglesias, esta documentación en algunas provincias muy concretas es de una riqueza insospechada. $Y$, por no hacernos más extensos, habría que volver a reiterar la necesidad de consultar las actas electorales como fuente primaria y fundamental.

Cuarta y última: También parece obligado hacer expresa mención de las Elecciones Generales de febrero de 1936. Para abordarlas en sus 
justos términos, es imprescindible estudiar y calibrar, en detalle, tanto la política represiva y de Orden público de las derechas durante el *Bienio Negro, como algunos datos sobre su específica política agraria. Sin determinar esto resultan arriesgadas cualquier tipo de interpretaciones sobre la victoria o derrota de la candidatura del Frente Popular. No valen aquí generalizaciones, sino estudios detallados sobre comunidades rurales concretas o comarcas para, sólo con posterioridad, abordar estudios de ámbito provincial o regional.

Ya hemos tenido oportunidad de señalar en qué consistió esa política represiva en el campo de manera que no vamos a insistir sobre ello. Asimismo, el estudio de la política agraria nos conduce ciertamente a introducirnos en algunas de las esferas e incertidumbres vividas por muchos pequeños labradores, productores y campesinos en su opción de voto, muchos de ellos subordinados al sindicalismo agrario patronal, a las amenazas de deshaucios de los grandes propietarios, a la vuelta a los sistemas represivos de mano de obra, al sautoritarismo rural tradicionaln, en suma entre otras cosas, a los intentos de recristianización o reevangelización (tal y como ya hemos tenido oportunidad de señalarlo en otro trabajo) del campesinado por parte de la patronal agraria en su particular búsqueda de una base populista y demagógica, deben tenerse muy presentes, afinando al máximo y comenzando por estudios muy localizados.

Una vez más vuelven a ser imprescindibles la consulta de algunos de los archivos arriba citados: "Congreso de los Diputados"; ‘Histórico Nacional de Salamanca"; "Históricos Provinciales", "Municipales*, etc. Así como otros de reciente apertura para los investigadores, algunos con ciertas dificultades para su acceso como el de la *Real Academia de la Historia (legado Diego Angulo Losada), el *Archivo del Ministro Manuel Giménez Fernández" o el de la "Comunión Tradicionalista.

Queremos, por fin, terminar -abusando un minuto más de vuestro tiempo- señalando -y tomadlo como una opinión- la necesidad de incorporar a los tradicionales trabajos de sociología electoral realizados sobre la Segunda República en Andalucía, nuevas fuentes y perspectivas, al menos en lo que se refiere a ciertas fracciones sociales asentadas en las comunidades rurales, tanto si éstas pertenecieran a espacios ecológicos latifundiarios o minifundiarios. Durante los minutos anteriores hemos abordado algunas posibles claves o vías de estudio alternativas que, en cualquier caso, tienen la firme pretensión de -si me permitís expresarlo de una manera gráfica- exprimir todas las posibilidades que ofrecen las fuentes documentales y archivísticas, en muchas casos francamente infrautilizadas. Así como la necesidad de acudir a la transdisciplinariedad en los estudios de cualquiera de las realidades socio-históricas andaluzas, y trabajos (antropología, sociología, historia social, politología, econo- 
mía, etc.) como los de -aquí no hacemos distinciones metodológicas e ideológicas entre los autores que vamos a mencionar porque sólo los expresamos como una muestra-: Pitt Rivers, Luque Baena, Hamza Alavi, Pío Navarro Alcalá-Zamora, Isidoro Moreno, Pérez Yruela, Sánchez Jiménez, Martínez Alier, etc., etc. pueden abrir más campos que cerrar o confundir el trabajo del historiador.

En cualquier caso para no hacernos más reiterativos queremos insistir en que las notas hasta ahora señaladas están -icómo no!- abiertas a nuevas sugerencias, a la aportación de nuevas fuentes $\mathrm{y}$, por último, quedan supeditadas a su discusión si así se desea.

\section{APENDICES}

\section{Cuadro I}

División en distritos electorales en 1913 Andalucía oriental (Almería, Granada y Málaga) Andalucía occidental (Cádiz y Sevilla)

\begin{tabular}{|c|c|c|c|c|}
\hline Provincia & Distrito & $N^{2}$ ayuntamientos & $\mathrm{N}^{2}$ secc. electorales & $\mathrm{N}^{2}$ de Electores \\
\hline \multirow[t]{6}{*}{ ALMERIA } & Almeria (3) & 47 & 97 & 32.770 \\
\hline & Berja (1) & 5 & 23 & 6.286 \\
\hline & Purchena (1) & 23 & 39 & 13.289 \\
\hline & Sorbas (1) & 10 & 39 & 12.170 \\
\hline & Vélez-Rubio (1) & 7 & 31 & 11.258 \\
\hline & Vera (1) & 11 & 43 & 14.160 \\
\hline \multirow[t]{9}{*}{ GRANADA } & Albuñol (1) & 21 & 32 & 7.598 \\
\hline & Alhama (1) & 30 & 39 & 11.174 \\
\hline & Baza (1) & 23 & 36 & 12.847 \\
\hline & Granada (3) & 42 & 96 & 31.190 \\
\hline & Guadix (1) & 29 & 41 & 12.684 \\
\hline & Huéscar (1) & 10 & 42 & 15.402 \\
\hline & Loja (1) & 6 & 35 & 13.816 \\
\hline & Motril (1) & 13 & 29 & 10.005 \\
\hline & Orgiva (1) & 30 & 36 & 8.343 \\
\hline \multirow[t]{9}{*}{ MALAGA } & Antequera (1) & 6 & 25 & 11.535 \\
\hline & Archidona (1) & 13 & 31 & 11.555 \\
\hline & Campillos (1) & 12 & 35 & 11.512 \\
\hline & Coín (1) & 11 & 32 & 12.206 \\
\hline & Gaucín (1) & 18 & 32 & 10.407 \\
\hline & Mâlaga (3) & 9 & 84 & 35.820 \\
\hline & Ronda (1) & 10 & 31 & 11.447 \\
\hline & Torrox (1) & 14 & 26 & 8.395 \\
\hline & Vélez-Málaga (1) & 9 & 28 & 9.579 \\
\hline \multirow[t]{6}{*}{ CADIZ } & Algeciras (1) & 6 & 46 & 18.460 \\
\hline & Cádiz (3) & 4 & 57 & 24.374 \\
\hline & Grazalema (1) & 13 & 37 & 12.763 \\
\hline & Jerez (3) & 11 & 82 & 30.102 \\
\hline & Medina Sidonia (1) & 4 & 29 & 11.024 \\
\hline & Pto. Sta. María (1) & 4 & 26 & 8.994 \\
\hline
\end{tabular}




$\begin{array}{llccc}\text { Provincia } & \text { Distrito } & \text { No ayuntamientos } & \text { No secc. electorales } & \text { No de Electores } \\ \text { CORDOBA } & \text { Cabra (1) } & 6 & 35 & 13.196 \\ & \text { Córdoba (3) } & 20 & 102 & 39.833 \\ & \text { Hinojosa d. Duque (1) } & 17 & 55 & 20.113 \\ & \text { Lucena (1) } & 6 & 36 & 13.654 \\ & \text { Montilla (1) } & 6 & 42 & 13.825 \\ & \text { Posadas (1) } & 13 & 42 & 15.078 \\ & \text { Priego de Córdoba (1) } & 7 & 35 & 12.620 \\ \text { SEVILLA } & \text { Carmona (1) } & 4 & 25 & 10.174 \\ & \text { Cazalla (1) } & 12 & 41 & 15.901 \\ & \text { Ecija (1) } & 4 & 24 & 9.280 \\ & \text { Estepa (1) } & 15 & 35 & 12.348 \\ & \text { Marchena (1) } & 3 & 29 & 10.238 \\ & \text { Morón (1) } & 8 & 31 & 11.226 \\ & \text { Sanlúcar Mayor (1) } & 17 & 34 & 12.059 \\ & \text { Sevilla (5) } & 32 & 143 & 57.872 \\ & \text { Utrera (1) } & 5 & 35 & 13.350\end{array}$

Fuente: Congreso de los Diputados, División del territorio de la Península e islas Baleares y Canarias en distritos electorales para diputados a Cortes. Madrid, Imp. y encuad. de Valentín Tordesillas, 1913. (Entre paréntesis el $\mathrm{n}^{2}$ de diputados que se eligen). 


\section{Cuadro II}

Personal subalterno y de Guardería municipal (1917-1936)

\begin{tabular}{|c|c|c|c|c|c|}
\hline Pueblo & Población & $1917-1931$ & $1931-1933$ & $1933-1936$ & Total \\
\hline Algarinejo & 7.489 &,--- &,--- & 100,0 & $11\left(^{*}\right)$ \\
\hline Alhama & 8.204 & 50,0 &,-- & 50,0 & $8(")$ \\
\hline Alhendín & 3.933 & 40,0 &,--- & 60,0 & $10(*)$ \\
\hline Alquife & 1.605 & 50,0 & 16,6 & 33,3 & $6(*)$ \\
\hline Atarfe & 4.979 & 45,4 &,--- & 54,5 & $11(*)$ \\
\hline Beas de Granada & 760 & $\cdots$ &,-- & 100,0 & 2 \\
\hline Benamaurel & 3.826 & 25,0 & 12,5 & 62,5 & 8 \\
\hline Castril & 4.872 & 75,0 &,--- & 25,5 & $4\left({ }^{*}\right)$ \\
\hline Cortes de Baza & 2.928 &,--- & 25,0 & 75,0 & $4\left({ }^{*}\right)$ \\
\hline Cúllar Baza & 8.515 &,-- &,--- & 100,0 & $18(*)$ \\
\hline Churriana & 2.361 & 33,3 &,-- & 66,6 & 6 \\
\hline Galera & 4.840 & 33,3 & 8,3 & 58,3 & 12 \\
\hline Gor & 5.532 & 23,0 & 7,7 & 69,3 & $13(*)$ \\
\hline Guadix & $21: 949$ & 75,0 & 10,7 & 14,3 & $28\left(^{*}\right)$ \\
\hline Guájar Faragüit & 1.251 &,-- &,-- & 100,0 & $2\left({ }^{*}\right)$ \\
\hline Huéscar & 9.429 & 42,1 & 26,3 & 31,6 & $19\left(^{*}\right)$ \\
\hline Iznalloz & 5.562 & 56,2 & 12,5 & 31,3 & $16(*)$ \\
\hline Loja & $21: 021$ & 27,7 & 13,6 & 56,1 & $44(*)$ \\
\hline Mondújar & 587 &,-- &,-- & 100,0 & $2(*)$ \\
\hline Montefrío & 14.380 &,-- &,--- & 100,0 & $17(*)$ \\
\hline Murchas & 412 &,-- &,--- & 100,0 & $1(*)$ \\
\hline Orgiva & 5.619 & 41,6 & 33,3 & 25,1 & $12\left(^{*}\right)$ \\
\hline Puebla D. Fadrique & 7.797 & 50,0 & 10,0 & 40,0 & $10(*)$ \\
\hline Pedro Martínez & 3.184 & $-\cdots,-$ &,--- & 100,0 & $5\left({ }^{*}\right)$ \\
\hline Salobreña & $5: 732$ & 46,6 & 13,3 & 40,1 & $15\left(^{*}\right)$ \\
\hline Sta. Cruz de Comercio & o 1.046 &,-- &,-- & 100,0 & 4 \\
\hline Válor & 1.226 &,-- &,--- & 100,0 & 5 \\
\hline
\end{tabular}

Fuente: Boletín Oficial de la Provincia de Granada: 1931-36. Elaboración propia.

(")- Localidad con Puesto de la Guardia Civil.

Nota: las cifras de las columnas hacen referencia a porcentajes 


\section{Cuadro III}

Distribución comarcal en porcentajes de los Ayuntamientos de la provincia de Granada (1931-1935)

\begin{tabular}{lrrrrrrrrr} 
COMARCAS & \multicolumn{2}{c}{ Abril } & 1931 & \multicolumn{2}{c}{ Mayo } & 1931 & \multicolumn{2}{c}{ Octubre 1932} & \multicolumn{2}{c}{ Enero 1935 } \\
& Dch. & Izq. & Dch. & Izq. & Dch. & Izq. & Dch. & Izq. \\
Alhama & 97,7 & 2,3 & 19,8 & 65,5 & 15,5 & 84,5 & 57,1 & s/d \\
Alpujarra & 94,3 & 0,5 & 42,3 & 54,1 & 67,7 & 32,3 & 54,3 & s/d \\
Baza & 78,4 & 2,0 & 42,1 & 57,9 & 70,2 & 29,8 & 42,8 & s/d \\
Costa & 78,5 & 3,1 & 28,7 & 63,9 & 32,0 & 68,0 & 58,3 & s/d \\
Guadix & 62,7 & $\mathbf{8 , 0}$ & 50,0 & 50,0 & 53,0 & 47,0 & 76,2 & s/d \\
Huéscar & 67,5 & 0,0 & 58,0 & 42,0 & 71,2 & 28,8 & 16,7 & s/d \\
Lecrín & 79,4 & 4,1 & 54,5 & 45,5 & 62,8 & 37,2 & 64,2 & s/d \\
Loja & 74,6 & 25,4 & 18,4 & 81,6 & 27,0 & 73,0 & 60,0 & s/d \\
Marquesado & 37,5 & 2,1 & 27,0 & 73,0 & 61,0 & 39,0 & 80,0 & s/d \\
Montes & 47,0 & $\mathbf{8 , 6}$ & 21,5 & 78,5 & 38,0 & 62,0 & 76,2 & s/d \\
Sierra Nevada & 68,5 & 1,8 & 6,8 & 93,2 & 41,7 & 58,3 & 66,7 & s/d \\
Vega & 54,8 & 26,8 & 21,0 & 79,0 & 33,9 & 66,1 & 74,3 & s/d
\end{tabular}

FUENTE: Archivo Diputación Provincial de Granada: -Actas electorales-, Sección Elecciones, legs. ns 13, 17, 19, 19 bis, 20 y 145 y legs. ns 21 a 25; El Defensor (7, 8, 14, 15 y 16-IV-1931, 2 a 10-VI-1931); Archivo de la Administración General del Estado (Gobernación): «Gobiemo civil de la provincia de Granada. Relación de Ayuntamientos de esta provincia con expresión numérica de los concejales que lo integran y grupo político a que pertenecen en $1^{0}$ de Octubre e 1932- caja no 121 y Archivo Histórico Nacional (Salamanca), Sección Político Social de Madrid: carpeta $n^{\circ} 993$. Elaboración propia.

Nota: Las columnas que no dan como resultado el 100 por cien corresponden a datos desconocidos.

Nota sobre las fuerzas políticas representadas:

1.- Columna Abril 1931 (Dch- monárquicos conservadores y liberales; Izq- socialistas y republicanos.

2.- Colùmna Mayo 1931 (Dch= monárquicos y republicanos de centro-derecha y derecha; Izq= socialistas y republicanos de centro-izquierda).

3.- Columna Octubre 1932 (Dch- republicanos de centro y derecha; Izq= socialistas y republicanos de izquierda).

4.- Columna Enero 1935 (Dch- republicanos radicales). 